\title{
Development of 2-Methoxyhuprine as Novel Lead for Alzheimer's Disease Therapy
}

\author{
Eva Mezeiova ${ }^{1,2}$, Jan Korabecny ${ }^{1,2} \mathbb{E}^{(0)}$, Vendula Sepsova ${ }^{1,3}$ (D), Martina Hrabinova ${ }^{1,3}$, \\ Petr Jost ${ }^{1,3}$, Lubica Muckova ${ }^{3}$, Tomas Kucera ${ }^{3}$, Rafael Dolezal ${ }^{1}$, Jan Misik ${ }^{1,3}$, \\ Katarina Spilovska 1,2, Ngoc Lam Pham 1,3, Lucia Pokrievkova ${ }^{4}$, Jaroslav Roh ${ }^{4}$, Daniel Jun 1,3, \\ Ondrej Soukup ${ }^{1,2}$, Daniel Kaping ${ }^{2}$ and Kamil Kuca 1,5,* \\ 1 Biomedical Research Centre, University Hospital Hradec Kralove, Sokolska 581, 50005 Hradec Kralove, \\ Czech Republic; eva.mezeiova@gmail.com (E.M.); korabecny.jan@gmail.com (J.K.); \\ vsepsova@gmail.com (V.S.); martina.hrabinova@unob.cz (M.H.); petr.jost@unob.cz (P.J.); \\ rafael.dolezal@fnhk.cz (R.D.); honzamisik@seznam.cz (J.M.); k.spilovska@gmail.com (K.S.); \\ phama92@gmail.com (N.L.P.); daniel.jun@unob.cz (D.J.); ondrej.soukup@fnhk.cz (O.S.) \\ 2 National Institute of Mental Health, Topolova 748, 25067 Klecany, Czech Republic; Daniel.Kaping@nudz.cz \\ 3 Department of Toxicology and Military Pharmacy, Faculty of Military Health Sciences, University of Defence \\ in Brno, Trebesska 1575, 50001 Hradec Kralove, Czech Republic; lubica.muckova@unob.cz (L.M.); \\ kucera-t@email.cz (T.K.) \\ 4 Department of Organic and Biorganic Chemistry, Faculty of Pharmacy in Hradec Kralove, \\ Charles University, Heyrovskeho 1203, 50005 Hradec Kralove, Czech Republic; \\ elpokrievkova@gmail.com (L.P.); rohj@faf.cuni.cz (J.R.) \\ 5 Department of Chemistry, Faculty of Science, University of Hradec Kralove, \\ Rokitanskeho 62, 50003 Hradec Kralove, Czech Republic \\ * Correspondence: kamil.kuca@fnhk.cz; Tel.: +420-495-833-447
}

Received: 3 July 2017; Accepted: 22 July 2017; Published: 28 July 2017

\begin{abstract}
Tacrine (THA), the first clinically effective acetylcholinesterase (AChE) inhibitor and the first approved drug for the treatment of Alzheimer's disease (AD), was withdrawn from the market due to its side effects, particularly its hepatotoxicity. Nowadays, THA serves as a valuable scaffold for the design of novel agents potentially applicable for AD treatment. One such compound, namely 7-methoxytacrine (7-MEOTA), exhibits an intriguing profile, having suppressed hepatotoxicity and concomitantly retaining AChE inhibition properties. Another interesting class of AChE inhibitors represents Huprines, designed by merging two fragments of the known AChE inhibitors-THA and (-)-huperzine A. Several members of this compound family are more potent human AChE inhibitors than the parent compounds. The most promising are so-called huprines $X$ and $Y$. Here, we report the design, synthesis, biological evaluation, and in silico studies of 2-methoxyhuprine that amalgamates structural features of 7-MEOTA and huprine $\mathrm{Y}$ in one molecule.
\end{abstract}

Keywords: acetylcholinesterase; Alzheimer's disease; butyrylcholinesterase; tacrine; 7-MEOTA; huprine Y; 2-methoxyhuprine

\section{Introduction}

Alzheimer's disease (AD) is neurodegenerative disorder which manifests itself in neurocognitive dysfunction (e.g., memory loss, behavioral abnormalities, depression, hallucinations, delusion, and agitation). The neuropathological changes associated with $\mathrm{AD}$ ultimately lead to consistent irreversible loss of neurons and synapses throughout the brain. This consequently results in the aggravation of $A D$ symptoms and finally in patient's death [1]. AD is considered one of the major public health issues due to the lack of effective treatment and demographic aging, which will increase the number of people suffering from $\mathrm{AD}$ in the future. The economic impact of $\mathrm{AD}$ is another important fact to consider $[2,3]$. 
The development of effective AD drug treatment builds upon pathomechanism understanding. One of the oldest hypothesis describing mechanisms of AD development support cholinergic dysfunction [1]. Accordingly, the alterations in cholinergic system (such as reduction of activity of different enzymes that are responsible for the synthesis end release of neurotransmitter acetylcholine (ACh)) lead to degeneration of cholinergic neurons and the disruption of cholinergic neurotransmission. Currently approved compounds for the treatment of mild to moderate AD stages-donepezil, rivastigmine, and galantamine provide symptomatic treatment by improving cholinergic neurotransmission via inhibition of acetylcholinesterase (AChE, E.C. 3.1.1.7.) to improve the quality of life of AD patients [1,4] (Figure 1).

Besides AChE inhibitors (AChEIs), memantine (Figure 1) has been approved for moderate to severe stages of $\mathrm{AD}$ treatment. Memantine acts as an $\mathrm{N}$-methyl-D-aspartate receptor (NMDAr) antagonist protecting against glutamate mediated excitotoxicity [1,4-6]. Also other approaches are currently extensively pursued; among others inhibitors of beta-secretase [7-9], direct inhibition of amyloid beta $(A \beta)$ overproduction [10], or their combination into one entity $[11,12]$.

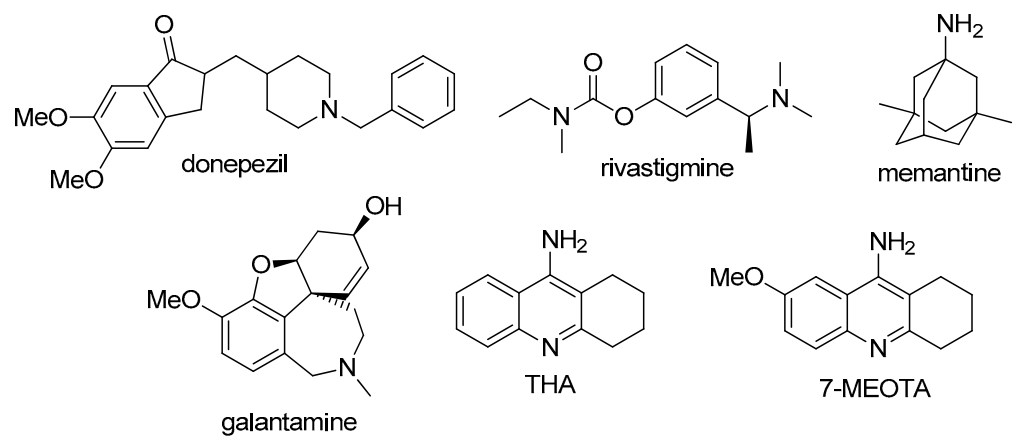

Figure 1. Structures of currently available drugs for the treatment of AD-donepezil, rivastigmine, memantine, and galantamine, and structures of THA and its methoxy derivative 7-MEOTA.

Other neuropathological changes associated with $\mathrm{AD}$ are intracellular neurofibrillary lesions composed of hyperphosphorylated tau protein and extracellular accumulation of $A \beta$ plagues [1,13-15]. Despite research efforts to develop novel therapeutics addressing A $\beta$ overload or tau hyperphosphorylation, it still lacks effectiveness resulting in AChEIs and memantin to remain the only approved AD drugs [16].

The first clinically used drug for the treatment of AD, THA (1,2,3,4-tetrahydro-9-aminoacridine), is centrally active, reversible AChEI. It was withdrawn from the market due to its poor oral bioavailability, the necessity of multiple day-doses, and a number of serious side effects such as hepatotoxicity, nausea, diarrhea, urinary incontinence, and potential carcinogenicity [17]. However, THA remains interesting for medicinal chemists involved in AD research as a scaffold for the development of novel lead compounds with better toxicological profile than the parent molecule. With this in mind, a THA derivative, 7-MEOTA, was developed [18,19]. 7-MEOTA retained the pharmacological profile of THA with lower occurrence of side effects. This lower toxicity can be ascribed to having a different metabolic pathway $[17,20]$.

\section{Design}

The essential idea behind the design of huprines was to find a lead molecule that will be able to span the active side of AChE as much as possible [21]. To achieve this aim, two known AChEIs were chosen. Indeed, huprines amalgamate structural motifs of THA (4-aminoquinoline system) and (-)-huperzine A (carbobicyclic bridged moiety). The development of huprines has been conceived empirically without any clear idea about the occupancy of huprine in the AChE active site. Further research has uncovered a divergent binding site for huprines as was predicted in the 
initial hypothesis. This fact has been corroborated in the following years by resolving 3D structures of the Torpedo californica AChE (TcAChE) enzyme with THA [22], (-)-huperzine A [23] and (-)-huprine $X$ [24]. In this regard, huprine $X(H u p X)$ and $Y(H u p Y)$ (Figure 2) represent the first generation of huprine analogues. These compounds are more than 100 times more potent AChEIs than the parent structures [21]. HupY ameliorated the signs of intoxication mediated via 3-nitropropionic acid (3-NP), natural toxin inducing neurodegeneration [25]. More importantly, it increased the survival of HupY pretreated mice in a 3-NP-induced assay without any alteration in body weight or muscular activity [26]. All these findings point to a neuroprotective action of HupY. Taking all these advantages together, we have combined the structural features of HupY with 7-MEOTA by exploiting a merging approach to yield 2-methoxyhuprine ((土)-1) (Figure 2). In this article, we report on the synthesis, biochemical studies, including cholinesterase inhibition, preliminary toxicity on HepG2 cell line, and in silico study in the human AChE (hAChE) and human BChE ( $h \mathrm{BChE}$ ) active sites.
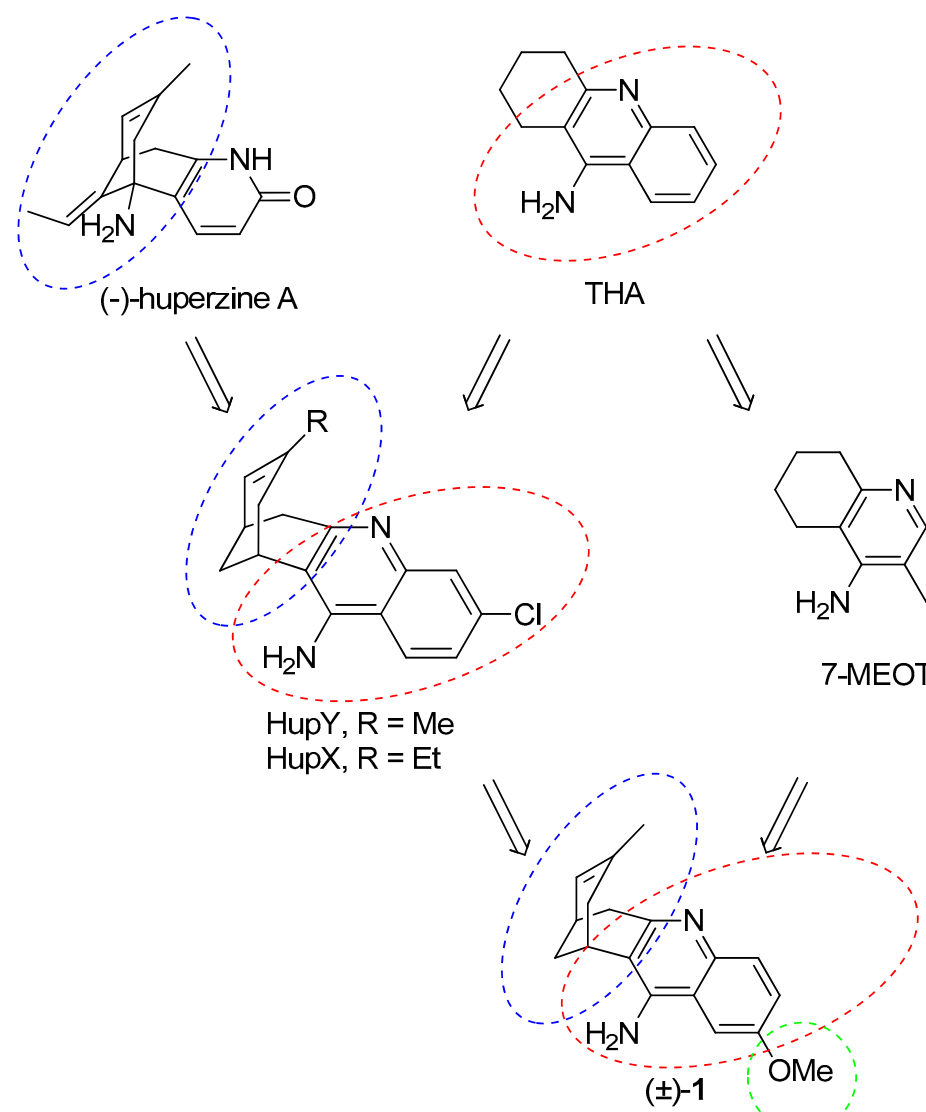

Figure 2. Design strategy towards 2-methoxyhuprine $( \pm)-\mathbf{1}$

\section{Results and Discussion}

\subsection{Synthesis}

The synthetic approach for the preparation of $( \pm)$-HupY and its 2-methoxy derivative $( \pm)-\mathbf{1}$ is depicted in Scheme 1. The synthesis followed the known two-step protocol [27,28]. The fragmentation reaction of commercially available 1,3-dibromoadamantane (2) or 1,3-adamantanediol (3) generated ketone 4 in $82 \%$ and $77 \%$ yields, respectively. Ketone 4 containing a vinyl functional group was than treated with $5 \% \mathrm{Pd} / \mathrm{C}$ in ethanol under hydrogen atmosphere. The isomerization of double bond under this condition led to a racemic mixture of compound ( \pm )-5 [28]. The crude product was used without any further purification in the next reaction. The final products were obtained by Friedlander-type 
condensation of ( \pm )-5 with 2-amino-4-benzonitrile (6) or 2-amino-5-methoxybenzonitrile (7) in the presence of aluminium trichloride as catalyst in 1,2-dichloroethane to yield $( \pm$ )-HupY or $( \pm)-\mathbf{1}$, respectively [29]. Both huprine derivatives $( \pm)$-HupY and $( \pm)-\mathbf{1}$ were then converted into corresponding hydrochlorides.

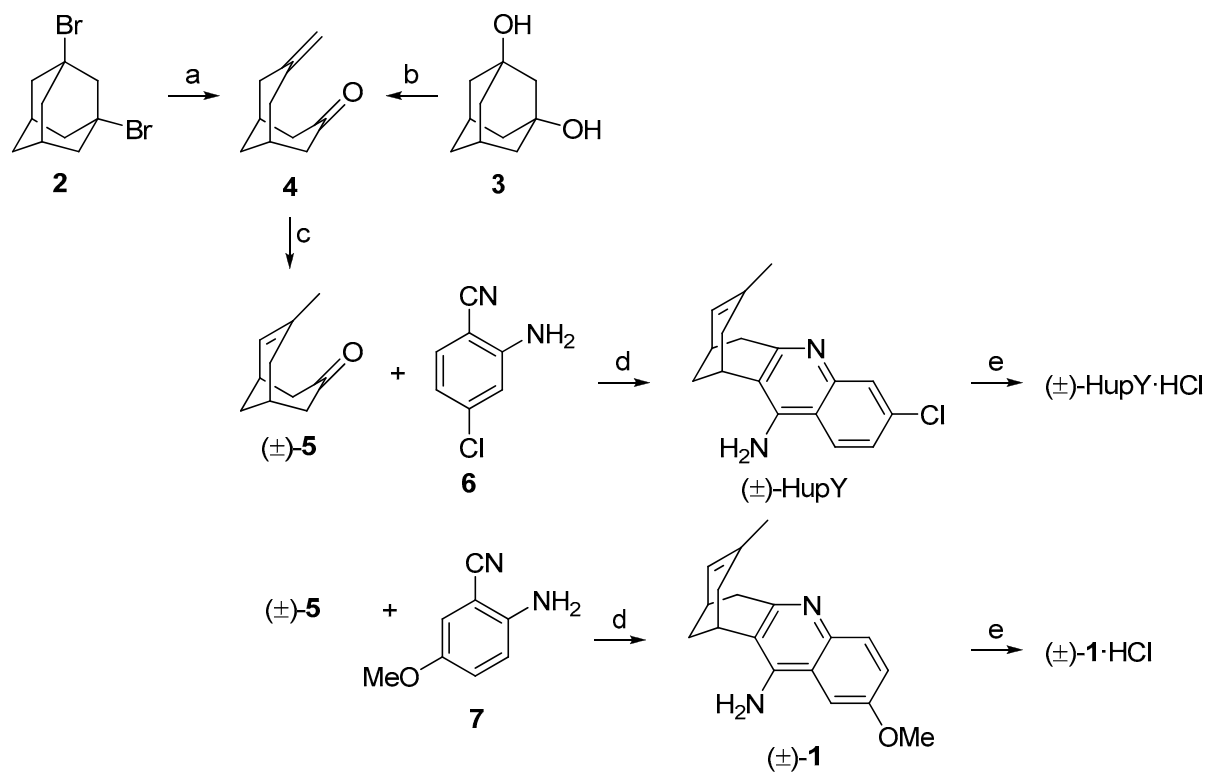

Scheme 1. Synthesis of $( \pm)-\mathrm{HupY} \cdot \mathrm{HCl}$ and $( \pm)-\mathbf{1} \cdot \mathrm{HCl}$. Reagents and conditions: (a) $1 \mathrm{M}$ $\mathrm{NaOH} / 1,4$-dioxane $(1: 1), 170{ }^{\circ} \mathrm{C}, 18 \mathrm{~h}, 82 \%$; (b) $p$-TsCl, DMAP, toluene, $130{ }^{\circ} \mathrm{C}(\mathrm{MW}), 1.5 \mathrm{~h}, 72 \%$; (c) $5 \% \mathrm{Pd} / \mathrm{C}, \mathrm{H}_{2}, \mathrm{EtOH}$, r.t., 2 h; (d) 6 or 7, $\mathrm{AlCl}_{3}, 1$,2-dichloroethane, ( \pm )-HupY, $81 \%$ after two steps, ( \pm -1, $80 \%$ after two steps; (e) $\mathrm{HCl}$, methanol, rt, overnight, $( \pm)-\mathrm{HupY} \cdot \mathrm{HCl}, 91 \%$, $( \pm)-\mathbf{1} \cdot \mathrm{HCl}, \mathbf{9 4} \%$.

\subsection{Evaluation of $A C h E$ and BChE Inhibition Activity}

AChE and BChE are members of the serine hydrolase family. They are responsible for the breakdown of choline-based structures being implicated in neurotransmission like ACh degradation by AChE/BChE or in detoxification of xenobiotics like cocaine, salicylic acid, and others by BChE [30,31]. Imbalance in ACh neurotransmission is regarded as one contributing aspect to the manifestation of symptoms related to disorders like AD, myasthenia gravis, glaucoma, Parkinson's disease, etc. [32,33]. Accordingly, ChEIs received particular attention in attenuating the symptoms in neurodegenerative disorders not only in AD [4].

The inhibitory activity of $( \pm)-\mathbf{1} \cdot \mathrm{HCl}$ towards $h \mathrm{AChE}$ and $h \mathrm{BChE}$ was determined by the modified spectrophotometric method described by Ellman et al. [34-37]. THA, 7-MEOTA, 6-chlorotacrine, and $( \pm)$-HupY $\cdot \mathrm{HCl}$ were used as reference compounds. The results are summarized in Table 1 and are expressed as $\mathrm{IC}_{50}$ values.

Initially, obtained results for the reference compounds are in good agreement with the literature data $[19,38,39]$. 2-Methoxyhuprine $( \pm)-\mathbf{1} \cdot \mathbf{H C l}$ showed inhibitory activity on a micromolar scale towards both ChEs. ( \pm -1 $\cdot \mathrm{HCl}$ displayed three orders of magnitude less potent inhibition than $( \pm)$-HupY $\cdot \mathrm{HCl}$ against $h \mathrm{AChE}$ which, in turn, revealed inhibitory activity on a one-digit nanomolar scale. 6-Chlorotacrine exerted two-digit nanomolar inhibition power, being two-fold more potent than $( \pm)$-1 $\cdot \mathrm{HCl}$. $( \pm)$-1 $\cdot \mathrm{HCl}$ yielded one order higher activity than 7-MEOTA, however, still being slightly less active than THA.

The present knowledge of pathophysiological mechanisms behind AD permits potential design of AChE-selective, non-selective ChE, and BChE-selective inhibitors [40]. The question, which remains open, is whether to focus our efforts on developing novel agents of a certain family of ChEIs. Selective BChEIs may have higher benefits in patients with moderate-to-severe stages of AD when the levels of 
AChE are depleted and BChE substitutes its role [41]. BChEIs can also mitigate the burden of $A \beta$ [42]. In the case of $\mathrm{AChE}$, the similar mode of action (A $\beta$ inhibition assembly) provided by direct $\mathrm{AChE}$ inhibition through its peripheral anionic site (PAS) gave rise to the so-called dual binding site strategy, i.e., ligands capable to interact with both anionic sites concomitantly [43,44]. Significantly, $( \pm)-\mathbf{1} \cdot \mathrm{HCl}$ demonstrated one-order higher $h \mathrm{BChE}$ affinity than 7-MEOTA and comparable potency to that of 6-chlorotacrine. $( \pm)$-1. $\mathrm{HCl}$ falls one order of magnitude behind $( \pm)$-HupY as well as THA, the latter having the highest inhibitory potency towards $h \mathrm{BChE}$ among all the tested compounds. Non-selective profile of $( \pm)-\mathbf{1} \cdot \mathrm{HCl}$ further underline the significance of this compound to be potentially used in any stages of $\mathrm{AD}$.

Table 1. Inhibitory activities of novel $( \pm)-\mathbf{1} \cdot \mathrm{HCl}$ and reference compounds $(( \pm)-\mathrm{HupY} \cdot \mathrm{HCl}, \mathrm{THA}$, 7-MEOTA and 6-chlorotacrine) for $h \mathrm{AChE}$ and $h \mathrm{BChE}$ expressed as $\mathrm{IC}_{50}$ values.

\begin{tabular}{cccc}
\hline \multirow{2}{*}{ Compound } & \multicolumn{2}{c}{ IC $_{\mathbf{5 0}} \pm \mathbf{S E M}(\boldsymbol{\mu M})^{\mathbf{a}}$} & \multirow{2}{*}{ Selectiviy for $\boldsymbol{h A C h E}^{\mathbf{b}}$} \\
\cline { 2 - 3 } & $\boldsymbol{h} \mathbf{A C h E}$ & $\boldsymbol{h B C h E}$ & 1.43 \\
\hline$( \pm)-\mathbf{1} \cdot \mathrm{HCl}$ & $2.63 \pm 0.36$ & $3.76 \pm 0.12$ & 218.29 \\
$( \pm)-\mathrm{HupY} \cdot \mathrm{HCl}$ & $0.00164 \pm 0.00014$ & $0.358 \pm 0.025$ & 0.68 \\
THA & $0.32 \pm 0.013^{\mathrm{c}}$ & $0.08 \pm 0.001^{\mathrm{c}}$ & 1.76 \\
7-MEOTA & $10.00 \pm 0.974^{\mathrm{c}}$ & $17.56 \pm 0.795^{\mathrm{c}}$ & 100.68 \\
6-chlorotacrine & $0.02 \pm 0.001^{\mathrm{c}}$ & $1.78 \pm 0.097^{\mathrm{c}}$ & \\
\hline
\end{tabular}

${ }^{\text {a }}$ Results are expressed as the mean of at least three experiments; ${ }^{\mathrm{b}}$ selectivity for $h \mathrm{AChE}$ is determined as ratio $\mathrm{IC}_{50}(h \mathrm{BChE}) / \mathrm{IC}_{50}(h \mathrm{AChE}){ }^{\mathrm{c}}{ }^{\mathrm{d}}$ data taken from Ref. [45-48].

\subsection{Kinetic Study of AChE Inhibition}

To evaluate the interactions of novel derivative $( \pm)-\mathbf{1} \cdot \mathrm{HCl}$ with $h \mathrm{AChE}$, a kinetic study was performed. Enzyme velocity curves were measured at various concentrations of substrate and tested compound. The type of inhibition was elucidated from the nonlinear regression analysis. Results for each type model of inhibition (competitive, non-competitive, uncompetitive, and mixed) were compared with sum-of-squares $F$-test.

Analysis indicated mixed type of inhibition $(p<0.05)$, consistent with graphical representation of Lineweaver-Burk plot in the Figure 3. The same type of inhibition was described in literature for parent compound HupY [49].

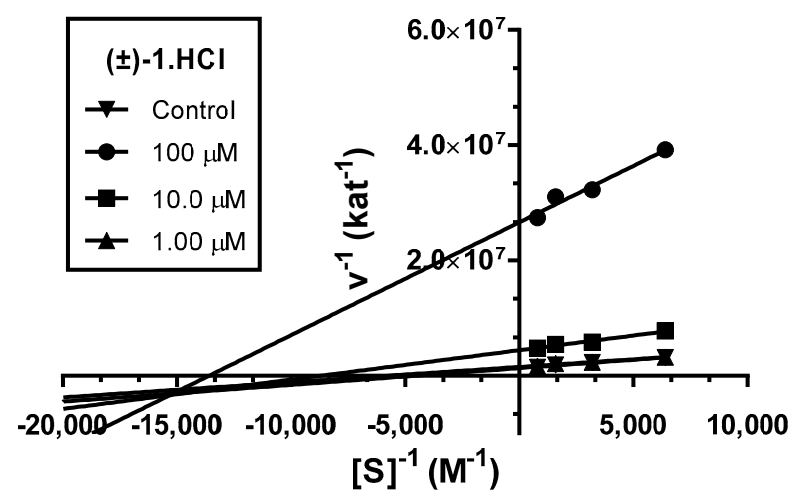

Figure 3. Steady-state inhibition of $h \mathrm{AChE}$ hydrolysis of substrate acetylthiocholine by novel huprine derivative $( \pm)-\mathbf{1} \cdot \mathrm{HCl}$ at different concentrations. Lineweaver-Burk plots of initial velocity at increasing substrate concentrations $(0.156-1.250 \mathrm{mM})$ are presented. Lines were derived from a linear regression of the data points.

The intersection of lines is placed below the $x$-axis. This indicates higher affinity to the enzyme-substrate complex than to the free enzyme $\left(K_{\mathrm{i}}>K_{\mathrm{i}^{\prime}}\right) . K_{\mathrm{m}}$ was slightly decreased, while 
the value of $V_{\max }$ decreased with higher concentration of $( \pm)-\mathbf{1} \cdot \mathrm{HCl}$. This means that the inhibitor binds reversibly to both the free enzyme and enzyme-substrate complex, affecting the binding of the substrate in the active site of $h \mathrm{AChE}$ and interacting with PAS. This causes conformational changes of the enzyme resulting also in changes in the active site. A corresponding $K_{\mathrm{i}}$ value of $16.4 \pm 1.3 \mu \mathrm{M}$ and $K_{\mathrm{i}^{\prime}}$ of $3.67 \pm 0.42 \mu \mathrm{M}$ was measured.

\subsection{In Vitro Blood-Brain Barrier Permeation and Druglikeness}

Anti-Alzheimer drugs are postulated to be centrally active, thus their effective permeation is necessary. To investigate the possibility of new huprine derivative $( \pm)-\mathbf{1} \cdot \mathrm{HCl}$ to cross the blood-brain barrier (BBB), a parallel artificial membrane permeation assay (PAMPA) was used [50,51]. ( \pm )-HupY is able to cross the BBB as suggested by previous ex vivo [39,49] and in vivo studies [26]. Our results from Table 2 clearly demonstrate that $( \pm)-\mathbf{1} \cdot \mathrm{HCl}$ as well as $( \pm)$-HupY $\cdot \mathrm{HCl}$ should be able to cross the BBB by passive diffusion, having $P_{\mathrm{e}}$ values above the standard drugs which are known to be CNS available (THA and donepezil). Negative controls (cefuroxime and piroxicam) are also reported. The higher $P_{\mathrm{e}}$ of $( \pm)-\mathbf{1} \cdot \mathrm{HCl}$ is indicative of its higher lipophilicity caused by the introduction of methoxy group.

Table 2. In vitro BBB permeability prediction for $( \pm)-\mathbf{1} \cdot \mathrm{HCl}$ and $( \pm)-\mathrm{HupY} \cdot \mathrm{HCl}$ as positive reference compound.

\begin{tabular}{|c|c|c|}
\hline \multirow{2}{*}{ Compound } & \multicolumn{2}{|c|}{ BBB Penetration Estimation } \\
\hline & $P_{\mathrm{e}} \pm \operatorname{SEM}\left(10^{-6} \mathrm{~cm} \cdot \mathrm{s}^{-1}\right)^{a}$ & CNS $(+/-)^{b}$ \\
\hline$( \pm)-\mathbf{1} \cdot \mathrm{HCl}$ & $7.64 \pm 0.22$ & $\mathrm{CNS}+$ \\
\hline$( \pm)-\mathrm{HupY} \cdot \mathrm{HCl}$ & $5.89 \pm 0.36$ & $\mathrm{CNS}+$ \\
\hline THA & $5.30 \pm 0.20^{c}$ & $\mathrm{CNS}+$ \\
\hline Donepezil & $7.3 \pm 0.9$ & $\mathrm{CNS}+$ \\
\hline 7-MEOTA & $6.50 \pm 1.85$ & $\mathrm{CNS}+$ \\
\hline 6-chlorotacrine & $5.00 \pm 0.45^{\mathrm{c}}$ & $\mathrm{CNS}+$ \\
\hline Cefuroxim & $2.70 \pm 0.1$ & CNS - \\
\hline Piroxicam & $2.20 \pm 0.15$ & CNS - \\
\hline
\end{tabular}

a Results are expressed as the mean of at least three experiments; ${ }^{\mathrm{b}} \mathrm{CNS}+$ : high BBB permeation predicted with $P_{\mathrm{e}}$ $\left(10^{-6} \mathrm{~cm} \cdot \mathrm{s}^{-1}\right)>4.0$, CNS - : low BBB permeation predicted with $P_{\mathrm{e}}\left(10^{-6} \mathrm{~cm} \cdot \mathrm{s}^{-1}\right)<2.0$, CNS $+/-$ : BBB permeation uncertain with $P_{\mathrm{e}}\left(10^{-6} \mathrm{~cm} \cdot \mathrm{s}^{-1}\right)$ from 4.0 to $2.0{ }^{c}{ }^{c}$ taken from references [52,53].

In order to address drug likeness of novel huprine $( \pm)-\mathbf{1} \cdot \mathrm{HCl}$, we have calculated its suitability in terms of balanced physicochemical properties, applying the CNS multiparameter optimization (MPO) algorithm (Table 3) [54]. This smart tool has been validated on a large dataset mainly composed from the library of Pfizer CNS drug candidates as well as marketed drugs. CNS MPO score uses a set of six physicochemical parameters (i) lipophilicity expressed as partition coefficient $(\mathrm{C} \log P)$; (ii) calculated distribution coefficient at $\mathrm{pH}=7.4\left(\mathrm{Clog} D_{7.4}\right)$; (iii) molecular weight (MW); (iv) topological polar surface area (TPSA); (v) number of hydrogen bond donors (HBD); and (vi) $\mathrm{p} K_{\mathrm{a}}$ value for the most basic center in the molecule $\left(\mathrm{CpK}_{\mathrm{a}}\right)$ [55]. All these parameters have been calculated by MarvinSketch 15.1.19.0 (Budapest, Hungary). The versatility of this tool lies in expanding the space for CNS active compounds where the violation of one of these psychicochemical characteristics does not necessarily mean the complete compounds exclusion from further testing. Following the CNS MPO algorithm, the calculated values for each specific psychicochemical parameter as well as CNS desirability can be found in Table 3. Accordingly, CNS MPO endpoints indicated that all the reference compounds as well as $( \pm)-\mathbf{1} \cdot \mathrm{HCl}$ fulfill the criteria for CNS drug candidates (CNS MPO $=4-6$ ). 
Table 3. Psychicochemical properties calculated by MarvinSketch 15.1.19.0 (Budapest, Hungary) and CNS MPO scores for $( \pm)-\mathbf{1} \cdot \mathrm{HCl}$ and standards under the survey.

\begin{tabular}{|c|c|c|c|c|c|c|c|}
\hline \multirow{2}{*}{ Compound } & \multicolumn{6}{|c|}{ Physicochemical Properties } & \multirow{2}{*}{ CNS MPO Score $b$} \\
\hline & $\mathrm{Clog} P^{\mathrm{a}}$ & $C \log D_{7.4}{ }^{a}$ & TPSA $^{a}$ & MW $^{a}$ & HBD $^{a}$ & $\mathrm{Cp} K_{\mathrm{a}}{ }^{\mathrm{a}}$ & \\
\hline$( \pm)-\mathbf{1} \cdot \mathrm{HCl}$ & $\begin{array}{c}2.91 \\
(3.58 \pm 0.02)^{c}\end{array}$ & $\begin{array}{c}1.56 \\
(1.734)^{c}\end{array}$ & 49.39 & 280.36 & 2 & $\begin{array}{c}8.91 \\
(9.54 \pm 0.02)^{c}\end{array}$ & 5.0 \\
\hline$( \pm)$-HupY·HCl & 3.67 & 2.95 & 40.16 & 285.79 & 2 & 8.07 & 5.0 \\
\hline THA & 2.63 & 1.25 & 40.16 & 199.27 & 2 & 8.95 & 4.7 \\
\hline 7-MEOTA & 2.47 & 1.08 & 49.39 & 229.30 & 2 & 8.98 & 5.0 \\
\hline 6-chlorotacrine & 3.23 & 2.41 & 40.16 & 233.72 & 2 & 8.20 & 5.1 \\
\hline
\end{tabular}

a The optimal values for each specific physiochemical attribute for CNS active compounds is postulated to range in the following intervals: $C \log P=1-5 ; \operatorname{Cog} D_{7.4}=0-3 ; \mathrm{TPSA} \leq 60-70 ; \mathrm{MW} \leq 400 \mathrm{Da} ; \mathrm{HBD} \leq 3 ; \mathrm{Cp} K_{\mathrm{a}}=4-10$; $\mathrm{b}$ optimal CNS MPO score $=4-6$, calculated according to protocol from $[54,55]$; ${ }^{\mathrm{c}}$ experimentally determined values with Sirius T3 device.

\subsection{Cytotoxicity}

To evaluate the cytotoxic profile of 2-methoxyhuprine $( \pm)-\mathbf{1} \cdot \mathrm{HCl}$ and other AChEIs under the survey, a 3-(4,5-dimethylthiazol-2-yl)-2,5-diphenyltetrazolium bromide (MTT) assay [56] was carried out on human liver carcinoma (HepG2), human renal adenocarcinoma (ACHN), and human neuroblastoma (SH-SY5Y) cell lines. The data obtained from these measurements are summarized in Table 4. THA has been shown to cause reversible abnormalities in liver function, and the exact mechanism of its action toward hepatocytes has not been fully elucidated. However, the relationship between metabolic activation to its protein-reactive form and cytotoxic metabolites has been found in a study performed with human liver microsomes $[57,58]$. Some studies pointed out that THA induces early alteration in membrane fluidity, a process related to cytotoxicity [59]. The disrupted membrane integrity results in lactate dehydrogenase (LDH) leakage while the occurrence of alanine aminotransferase (ALT) elevation was reported as late-onset [60]. Keeping this in mind, we have evaluated the potential cytotoxic effect of novel huprine $( \pm)-\mathbf{1} \cdot \mathrm{HCl}$ and all the reference compounds. We found out that THA was the least toxic compound with $\mathrm{IC}_{50}$ values among $120-168 \mu \mathrm{M}$ for all the tested cell lines. The therapeutic plasma concentration of THA $(7-20 \mathrm{ng} / \mathrm{mL})$ associated with elevation in liver aminotransferases in human is substantially lower than in vitro cytotoxicity concentrations $[58,61]$. The second ranked compound with the lowest cytotoxicity can be considered 7-MEOTA and 6-chlorotacrine. Focusing on $( \pm)-\mathbf{1} \cdot \mathrm{HCl}$, the data indicated the similar cytotoxic profile as that found for $( \pm)-\mathrm{HupY} \cdot \mathrm{HCl}$ on $\mathrm{HepG} 2$ cell line, however, $( \pm$ )-HupY $\cdot \mathrm{HCl}$ is more cytotoxic than 7-MEOTA. Note that 7-MEOTA is considered a relatively safe THA derivative as proved in many in vivo studies $[17,19,20,45,62]$. Other important findings related to ACHN and SH-SY5Y cell lines suggested that $( \pm)-\mathbf{1} \cdot \mathrm{HCl}$ cytotoxicity lies behind the cytotoxicity profile of 6-chlorotacrine. This two kidney- and neuronal-origin cells lines were found more sensitive to both $( \pm)-\mathbf{1} \cdot \mathrm{HCl}$ and $( \pm)-\mathrm{HupY} \cdot \mathrm{HCl}$, respectively. From this point of view, molecular weight increment goes hand in hand with increasing cytotoxicity against all three cell lines. Taken together, this preliminary data has to be taken with precaution since they could not reflect the real toxicity profile of the compound under in vivo conditions.

Table 4. Results of cytotoxicity of $( \pm)-\mathbf{1} \cdot \mathrm{HCl}$ and reference compounds in HepG2, ACHN, and SH-SY5Y cell lines.

\begin{tabular}{cccc}
\hline \multirow{2}{*}{ Compound } & \multicolumn{3}{c}{ IC $_{\mathbf{5 0}} \pm$ SEM $(\boldsymbol{\mu M})^{\mathbf{a}}$} \\
\cline { 2 - 4 } & HepG2 & ACHN & SH-SY5Y \\
\hline$( \pm)-\mathbf{1} \cdot \mathrm{HCl}$ & $14.91 \pm 0.11$ & $32.22 \pm 0.72$ & $17.84 \pm 0.09$ \\
$( \pm)-\mathrm{HupY} \cdot \mathrm{HCl}$ & $15.87 \pm 1.17$ & $24.62 \pm 0.32$ & $17.49 \pm 0.44$ \\
THA & $168.47 \pm 3.63$ & $155.20 \pm 0.67$ & $120.63 \pm 1.97$ \\
7-MEOTA & $44.37 \pm 3.35$ & $49.27 \pm 2.69$ & $26.83 \pm 1.04$ \\
6-chlorotacrine & $43.20 \pm 1.17$ & $55.11 \pm 1.76$ & $50.40 \pm 1.28$ \\
\hline
\end{tabular}

\footnotetext{
a Results are expressed as the mean of at least three experiments, cytotoxic profile assessed after $24 \mathrm{~h}$.
} 


\subsection{In Silico Docking Studies}

The aforementioned biological data for $( \pm)-\mathbf{1} \cdot \mathrm{HCl}$ and $( \pm)$-HupY $\cdot \mathrm{HCl}$ represent the sum of effects for both enantiomers. Since the separation of the racemic mixture into pure enantiomers and successive biological evaluation was not feasible in our hands, we decided to inspect the binding modes for each enantiomer of $\mathbf{1} \cdot \mathrm{HCl}$ and compared it with HupY enantiomers. From the literature sources available, we found out that the more active isomer was (-)-HupY (correspond to 7S,11S-HupY), possessing $h \mathrm{AChE} \mathrm{IC} \mathrm{IC}_{50}=0.32 \mathrm{nM}$, over $(+)$-HupY $\left(7 R, 11 R\right.$-HupY) with $h \mathrm{AChE} \mathrm{IC}_{50}=123 \mathrm{nM}$. The same observation can be made for $h \mathrm{BChE}$ where (+)-HupY was slightly more active than (-)-HupY $\left((+)\right.$-HupY $h \mathrm{BChE} \mathrm{IC} \mathrm{IC}_{50}=153 \mathrm{nM} ;(-)$-HupY $\left.h \mathrm{BChE} \mathrm{IC}{ }_{50}=247 \mathrm{nM}\right)$ [39]. In order to predict more potent $h \mathrm{AChE}$ and $h \mathrm{BChE}$ enantiomer of $\mathbf{1} \cdot \mathrm{HCl}$ we have carried out the molecular modeling simulation on the models of $h \mathrm{AChE}$ (PDB ID: 4EY7) and $h \mathrm{BChE}$ (PDB ID: 4BDS) into their active sites [63,64].

Paying attention to $h \mathrm{AChE}$ (Figure 4 ), it has to be noted that $7 S, 11 S$-HupY as well as $7 R, 11 R$-HupY shared a high degree of spatial conformity. This includes (i) parallel $\pi-\pi$ stacking against Trp86; (ii) hydrogen bonding between an exocyclic amino group from HupY and an amino group from Asp74, as well as a hydroxyl group from Tyr124; and (iii) hydrophobic interaction with Tyr341. 7S,11S-HupY (Figure 4C,D) exerted slightly more favorable orientation than $7 R, 11 R$-HupY (Figure $4 A, B$ ) in the $h \mathrm{AChE}$ active site. This presumably stems from a closer spatial arrangement of HupY aromatic core to Tyr337 via $\pi-\pi /$ cation- $\pi$ contact (3.7 $\AA$ for $7 S, 11 S$-HupY; $4.4 \AA$ for $7 R, 11 R$-HupY) being attributed to less steric hindrance of carbobicyclic huprine moiety. Moreover, $7 S, 11 S-H u p Y$ adapted parallel cation- $\pi$ contact with Phe338. This type of interaction was not provided by $7 R, 11 R$-HupY. Estimated binding energies for each ligand were computed by Autodock Vina as follows $-12.6 \mathrm{kcal} / \mathrm{mol}$ and $-12.3 \mathrm{kcal} / \mathrm{mol}$ for $7 S, 11 S$-HupY and $7 R, 11 R$-HupY, respectively. Our results can be put into contrast with huprine derivative, namely HupX bearing ethyl appendage instead of methyl in HupY [24]. In this case, (-)HupX was co-crystalized with TcAChE indicating sandwich $\pi-\pi$ stacking between Trp84 and Phe330. This type of interaction is analogous to the lodging of 7S,11S-HupY (see Phe338 and Trp86, Figure 4C). In HupX-TcAChE complex, conserved water molecules mediated hydrogen bonding between amino group and some amino acid residues. Since we did not include water molecules into our experiments, the latter cannot be confirmed for the HupY- $h$ AChE complex. Lastly, methyl, carbobicyclic scaffold, and chlorine from (-)-HupY (Figure 4C,D) filled the same regions as HupX in TcAChE. All these findings underlie the validity of our experimental protocol.

Completely different poses were obtained for 7S,11S-1 (Figure 4E,F) and 7R,11R-1 (Figure 4G,H) in $h \mathrm{AChE}$ active site. Better ligand fitting was found for $7 S, 11 S-\mathbf{1}(-12.3 \mathrm{kcal} / \mathrm{mol})$ over $7 R, 11 R-\mathbf{1}$ $(-11.6 \mathrm{kcal} / \mathrm{mol})$. Interestingly, anchoring of $7 S, 11 S-1$ resembles the accommodation of $7 S, 11 S-H u p Y$ in $h$ AChE CAS subsite with several specific features outlined previously. Compared to $7 S, 11 S-1$, typical hydrogen bonds between exocyclic amino group of $\mathbf{1}$ and Asp74 and Tyr124 diminished when $7 R, 11 R-\mathbf{1}$ was embedded into the $h \mathrm{AChE}$ active site. On the contrary, $7 R, 11 R-\mathbf{1}$ was engaged in hydrogen bond formation between the methoxy group of $7 R, 11 R-1$ and the hydroxyl of Tyr133 (1.8 $\AA$ ) together with connection of the amino group of $7 R, 11 R-1$ to Ser203 (2.5 $)$ and Glu202 $(2.5 \AA)$, amino acid residues from the catalytic triad. Taking all these findings and aspects together and putting them in contrast with the known activity facts for each enantiomer of HupY, we assume that the more active $h \mathrm{AChE}$ enantiomer of $\mathbf{1}$ relates to $7 S, 11 S-\mathbf{1}$.

Very close $\mathrm{IC}_{50}$ values were experimentally determined for 7S,11S-HupY and 7R,11R-HupY against $h \mathrm{BChE}$ [39]. Our docking procedure was not able to sufficiently explain discrepancies behind the orientation of each enantiomer in $h \mathrm{BChE}$ active site $(7 R, 11 \mathrm{R}-\mathrm{Hup} Y-h \mathrm{BChE}$ complex is superimposed in Figure 5A,B; 7S,11S-HupY- $h$ BChE complex is rendered in Figure 5C,D). In general, the common structural features can be outlined as follows (i) face-to-face orientation of $\mathbf{1}$ aromatic part against Trp82 (3.8 $\AA$ and $3.6 \AA$ for 7R,11R-HupY and 7S,11S-HupY, respectively); (ii) hydrogen bond contact with carbonyl group from Gly78; and (iii) hydrophobic contact Trp82 and Tyr440. According to the calculated binding affinities, the more preferred $h \mathrm{BChE}$ binder can be highlighted as $7 R, 11 \mathrm{R}-\mathrm{HupY}$ 
over 7S,11S-HupY with estimated binding energies $-11.1 \mathrm{kcal} / \mathrm{mol}$ and $-10.7 \mathrm{kcal} / \mathrm{mol}$, respectively. This is also in line with data from literature [39].

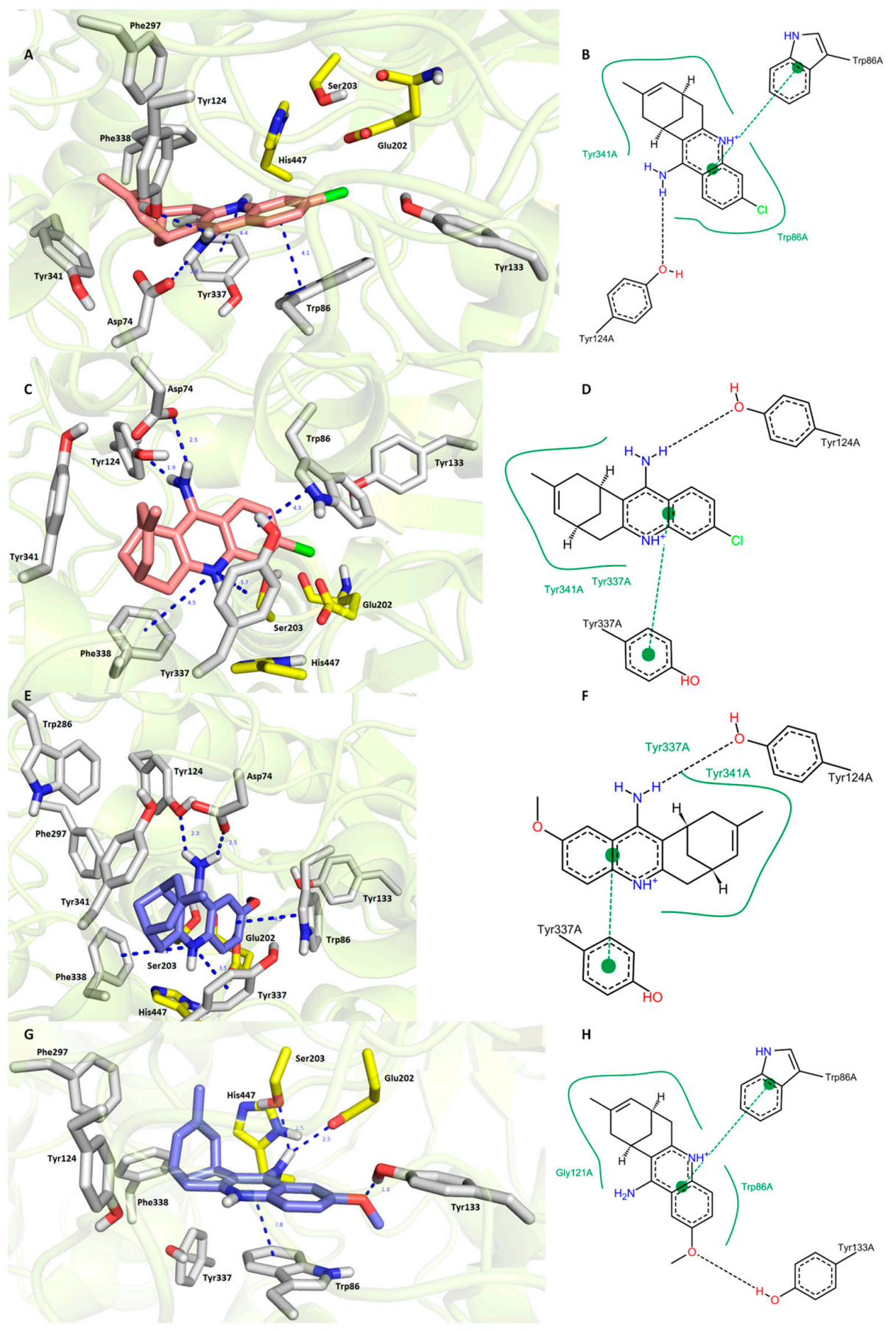

Figure 4. Docking results for HupY ((A,B)—7R,11R-HupY; (C,D)—7S,11S-HupY) and $\mathbf{1}((\mathbf{E}, \mathbf{F})$ - $7 S, 11 S-\mathbf{1}$; $(\mathbf{G}, \mathbf{H})-7 R, 11 R-\mathbf{1})$ within $h$ AChE active site (PDB ID: 4EY7). Generally to (A,C,E,G)—HupY is rendered in salmon carbon atoms; $\mathbf{1}$ is depicted in dark blue carbon atoms; important amino acid residues involved in the ligand-enzyme interactions are displayed in grey carbon atoms; catalytic triad residues (Glu202, Ser203, His447) are shown in yellow; rest of the enzyme is represented in grey cartoon; $(\mathbf{B}, \mathbf{D}, \mathbf{F}, \mathbf{H})-2 \mathrm{D}$ representation of binding modes of HupY and 1. (B,D,F,H) were created with PoseView software (PoseView, http:/ / poseview.zbh.uni-hamburg.de/poseview/wizard, 2012); (A,C,E,G) were generated with PyMol 1.30 (The PyMOL Molecular Graphics System, Version 1.5.0.4 Schrödinger, LLC.). 

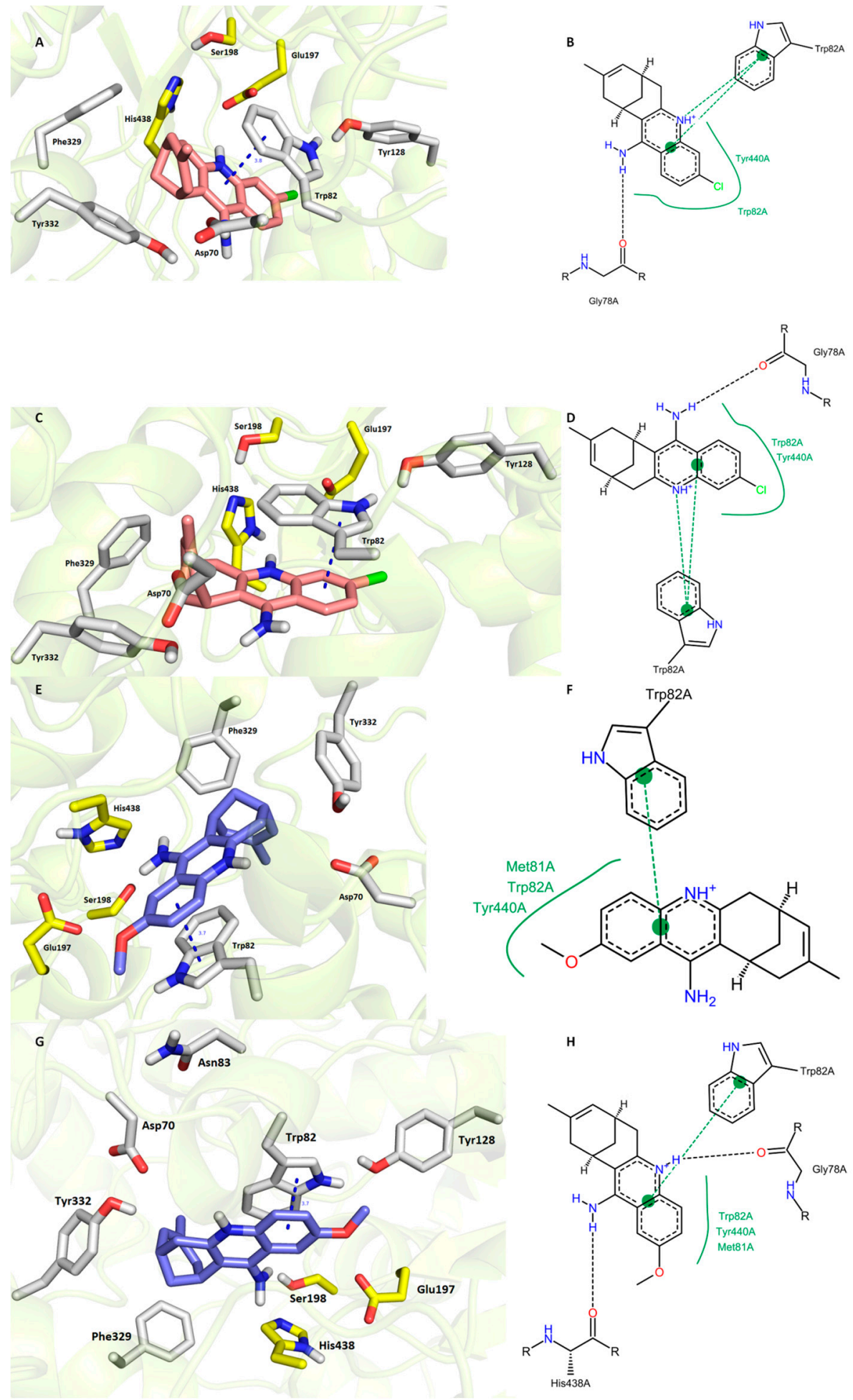

Figure 5. Docking results for HupY ((A,B)-7R,11R-HupY; (C,D)—7S,11S-HupY) and $\mathbf{1}((\mathbf{E}, \mathbf{F})-7 S, 11 S-\mathbf{1}$; $(\mathbf{G}, \mathbf{H})-7 R, 11 R-\mathbf{1})$ within $h \mathrm{BChE}$ active site (PDB ID: 4BDS). Generally to A, C, E, G-HupY is rendered in salmon carbon atoms; $\mathbf{1}$ is depicted in dark blue carbon atoms; important amino acid residues involved in the ligand-enzyme interactions are displayed in grey carbon atoms; catalytic triad residues (Glu198, Ser197, His438) are shown in yellow; rest of the enzyme is represented in grey cartoon; $(\mathbf{B}, \mathbf{D}, \mathbf{F}, \mathbf{H})-2 \mathrm{D}$ representation of binding modes of HupY and $\mathbf{1}$. (B, $\mathbf{D}, \mathbf{F}, \mathbf{H})$ were created with PoseView software (PoseView, http:/ / poseview.zbh.uni-hamburg.de/poseview/wizard, 2012); (A,C,E,G) were generated with PyMol 1.30 (The PyMOL Molecular Graphics System, Version 1.5.0.4 Schrödinger, LLC.). 
The docking simulation for 1 was able to distinguish and predict the more active enantiomer against $h \mathrm{BChE}$ (Figure 5E,F 7S,11S-1; G,H 7R,11R-1). Although both enantiomers occupied the same region of $h \mathrm{BChE}$, making $\pi-\pi$ contact with Trp 82 in the same distance $3.7 \AA$, few more interactions between ligand and enzyme can be observed for $7 \mathrm{R}, 11 R-1$. These are hydrogen bond connections between the heterocyclic nitrogen of 7R,11R-1 with the carbonyl group from Gly78 and the exocyclic amino group of 7R,11R-1 and His 438 from the catalytic triad. In the case of 7S,11S-1, the catalytic triad remained unaffected. The latter statement is also supported by the calculated binding energies for 7R,11R-1 and 7S,11S-1, which were $-11.3 \mathrm{kcal} / \mathrm{mol}$ and $-10.5 \mathrm{kcal} / \mathrm{mol}$, respectively. However, the real potential of each enantiomer has to be determined by in vitro experiments to unequivocally assess their inhibition capacity.

\section{Materials and Methods}

\subsection{General Chemistry Methods}

All chemical reagents and solvents were used in the highest available purity without further purification and were purchased from Sigma-Aldrich (Prague, Czech Republic). The reactions were monitored by thin layer chromatography (TLC) on silica gel plates (60 F254, Merck, Prague, Czech Republic) and the spots were visualized by either spraying with a solution of $p$-anisaldehyde and subsequent heating or with ultraviolet light $(254 \mathrm{~nm})$. A CEM Discover SP focused microwave reactor was used for microwave-mediated reactions. Purifications of crude products were carried out using silica gel columns (silica gel 100, 0.063-0.200 mm, 70-230 mesh ASTM, Fluka, Prague, Czech Republic). The microwave-mediated reactions were performed using a CEM Discover SP focused microwave reactor. NMR spectra were recorded in deuterated chloroform $\left(\mathrm{CDCl}_{3}\right)$, deuterated methanol $\left(\mathrm{CD}_{3} \mathrm{OD}\right)$ or deuterated dimethyl sulfoxide (DMSO- $d_{6}$ ) on a Varian 5500 spectrometer. Chemical shifts $(\delta)$ are reported in parts per millions (ppm) and spin multiplicities are given as singlet (s), broad singlet (bs), doublet (d), or multiplet (m). Coupling constants $(J)$ are reported in Hz. Melting points were determined using automated melting point recorder M-565 (Büchi, Switzerland) and are uncorrected. The synthesized compound $( \pm)-\mathbf{1} \cdot \mathrm{HCl}$ was analyzed by LC-MS system consisting of UHPLC Dionex Ultimate 3000 coupled with Q Exaxtive Plus mass spectrometer to obtain high resolution mass spectra (Thermo Fisher Scientific, Bremen, Germany). Elemental analyses were obtained in a satisfactory range, confirming $>95 \%$ purity.

\subsubsection{Preparation of 7-Methylenebicyclo[3.3.1]nonan-1-one (4)}

A suspension of $2(200 \mathrm{mg}, 0.68 \mathrm{mmol})$ in $4.2 \mathrm{~mL}$ of a mixture of $1 \mathrm{M} \mathrm{NaOH} / 1$,4-dioxane (1:1) was stirred at $175^{\circ} \mathrm{C}$ for $18 \mathrm{~h}$ in an autoclave. The mixture was poured into ethyl-acetate $(8 \mathrm{~mL})$ and washed with water $(4 \mathrm{~mL})$. The aqueous phase was washed with another portion of ethyl-acetate $(8 \mathrm{~mL})$. The combined organic layers were dried over anhydrous $\mathrm{Na}_{2} \mathrm{SO}_{4}$ and concentrated under reduced pressure. Crude product was purified by column chromatography (petroleum-ether/ethyl-acetate, 4:1). Ketone $4(84 \mathrm{mg})$ was obtained in $82 \%$ as white crystals.

Alternative approach for 4: A suspension of $3(250 \mathrm{mg}, 1.49 \mathrm{mmol}), p-\mathrm{TsCl}(708 \mathrm{mg}, 3.74 \mathrm{mmol})$ and DMAP (454 mg, $3.74 \mathrm{mmol})$ in dry toluene $(5.4 \mathrm{~mL})$ was stirred at $130{ }^{\circ} \mathrm{C}$ for $1.5 \mathrm{~h}$ under MW conditions. The crude reaction mixture was filtered-off and filtrate was concentrated under reduced pressure. The ketone was purified by column chromatography (petroleum-ether/ethyl-acetate, 4:1) to afford compound $4(172 \mathrm{mg})$ in $77 \%$ yield.

${ }^{1} \mathrm{H}$ - and ${ }^{13} \mathrm{C}-\mathrm{NMR}$ spectra were in good agreement with published data $[27,28]$.

4.1.2. Preparation of rac-7-Chloro-15-methyl-10-azatetracyclo[11.3.1. $\left.0^{2,11} \cdot 0^{4,9}\right]$ heptadeca-2(11),3,5,7,9,14hexaen-3-amine hydrochloride $(( \pm)-\mathrm{HupY} \cdot \mathrm{HCl})$

A suspension of ketone $4(105 \mathrm{mg}, 0.70 \mathrm{mmol})$ and $5 \% \mathrm{Pd} / \mathrm{C}(19.4 \mathrm{mg})$ in absolute ethanol $(2.1 \mathrm{~mL})$ was stirred under $\mathrm{H}_{2}$ atmosphere for $2 \mathrm{~h}$. After the end of isomerization, the catalyst was filtered-off 
using filter paper and the filtrate was concentrated under reduced pressure. The crude product $( \pm)-5$ was used to the following reaction without any purification. ${ }^{1} \mathrm{H}$ and ${ }^{13} \mathrm{C}-\mathrm{NMR}$ spectra were in good agreement with published data $[27,28]$.

To the solution of compound $( \pm)-5$ (92 $\mathrm{mg}, 0.615 \mathrm{mmol})$ in 1,2-dichloroethane (1 mL), anhydrous $\mathrm{AlCl}_{3}(123 \mathrm{mg}, 0.92 \mathrm{mmol})$ and $6(117 \mathrm{mg}, 0.77 \mathrm{mmol})$ were added. The reaction mixture was stirred at $95{ }^{\circ} \mathrm{C}$ (MW-50 W, $300 \mathrm{psi}$, high stirring) for $2 \mathrm{~h}$. After cooling down to room temperature, THF $(5 \mathrm{~mL})$ and water $(2.5 \mathrm{~mL})$ were added, followed by addition of $2 \mathrm{M}$ aq. solution of $\mathrm{NaOH}$ to adjust $\mathrm{pH}$ to $8-9$. The resulting mixture was stirred for additional $30 \mathrm{~min}$. The aq. phase was washed with dichloromethane $(2 \times 8 \mathrm{~mL})$. Combined organic layers were dried over anhydrous $\mathrm{Na}_{2} \mathrm{SO}_{4}$ and concentrated under reduced pressure. The residue was submitted to column chromatography (petroleum-ether/ethyl-acetate, 4:1) to give ( \pm )-HupY (161 mg, 81\% yield in two steps) as a slightly yellow solid.

Compound $( \pm)$-HupY $(70 \mathrm{mg})$ was dissolved in methanol $(1 \mathrm{~mL})$ and then $2 \mathrm{M} \mathrm{HCl}$ in methanol $(1 \mathrm{~mL})$ was added. The mixture was stirred over night at room temperature. The solvents were evaporated under reduced pressure. The final product $( \pm)$ - $\mathrm{HupY} \cdot \mathrm{HCl}(72 \mathrm{mg})$ was obtained in $91 \%$ yield. Spectral data were in good agreement with published data [29].

4.1.3. Preparation of rac-6-Methoxy-15-methyl-10-azatetracyclo[11.3.1. $\left.0^{2,11} \cdot 0^{4,9}\right]$ heptadeca-2(11),3,5,7,9,14hexaen-3-amine hydrochloride $(( \pm)-\mathbf{1} \cdot \mathrm{HCl})$

To the solution of ketone 4 (108 mg, $0.72 \mathrm{mmol})$ in absolute ethanol $(2.2 \mathrm{~mL}) 5 \% \mathrm{Pd} / \mathrm{C}(20 \mathrm{mg})$ was added. The reaction mixture was stirred under $\mathrm{H}_{2}$ atmosphere for $2 \mathrm{~h}$. The catalyst was removed by filtration through filter paper and the filtrate was concentrated under reduced pressure. Compound $( \pm)-5$ was used to the next reaction without further purification. ${ }^{1} \mathrm{H}-$ and ${ }^{13} \mathrm{C}-\mathrm{NMR}$ spectra were in good agreement with published data $[27,28]$.

Ketone $( \pm)-5$ (95 mg, $0.63 \mathrm{mmol})$ was dissolved in dry 1,2-dichloroethane (1 mL). Anhydrous $\mathrm{AlCl}_{3}(126.5 \mathrm{mg}, 0.95 \mathrm{mmol})$ and $7(121 \mathrm{mg}, 0.79 \mathrm{mmol})$ were added to this solution. The mixture was stirred under MW ( $50 \mathrm{~W}, 300 \mathrm{psi}$, high stirring) conditions at $95^{\circ} \mathrm{C}$ for $2 \mathrm{~h}$. After the completion of the condensation, mixture of THF $/ \mathrm{H}_{2} \mathrm{O}(7.5 \mathrm{~mL}, 2: 1)$ was added, followed by $2 \mathrm{M}$ aq. solution of $\mathrm{NaOH}$ adjusting $\mathrm{pH}$ to $8-9$. The resulting mixture was stirred for $30 \mathrm{~min}$. The organic and aqueous phases were separated and the aqueous one was washed with dichloromethane $(2 \times 8 \mathrm{~mL})$. Combined organic layers were dried over anhydrous $\mathrm{Na}_{2} \mathrm{SO}_{4}$ and the solvent was removed under reduced pressure. The crude product was purified by column chromatography $\left(\mathrm{CH}_{2} \mathrm{Cl}_{2} / \mathrm{MeOH} / \mathrm{TEA}, 95: 5: 1\right)$. Compound $( \pm)-\mathbf{1}(142 \mathrm{mg})$ was obtained in $80 \%$ yield in two steps as a white solid.

$2 \mathrm{M} \mathrm{HCl}$ in methanol $(1 \mathrm{~mL})$ was added to the solution of $( \pm)-\mathbf{1}(70 \mathrm{mg}, 0.25 \mathrm{mmol})$ in methanol $(1 \mathrm{~mL})$. The reaction mixture was stirred overnight and then solution was evaporated under reduced pressure. Hydrochloride $( \pm)-\mathbf{1} \cdot \mathbf{H C l}(74 \mathrm{mg})$ was obtained in $94 \%$ yield as a slightly yellow solid, m.p. $280{ }^{\circ} \mathrm{C}$ compound decomposition. ${ }^{1} \mathrm{H}-\mathrm{NMR}\left(\mathrm{DMSO}-d_{6}\right): \delta 7.97\left(\mathrm{~d}, J=2.7 \mathrm{~Hz}, 1 \mathrm{H}, \mathrm{H}_{1}\right), 7.90(\mathrm{~d}$, $\left.J=9.2 \mathrm{~Hz}, 1 \mathrm{H}, \mathrm{H}_{4}\right), 7.48\left(\mathrm{dd}, J=9.2,2.6 \mathrm{~Hz}, 1 \mathrm{H}, \mathrm{H}_{3}\right), 5.49\left(\mathrm{~d}, J=5.2 \mathrm{~Hz}, 1 \mathrm{H}, \mathrm{H}_{8}\right), 3.91\left(\mathrm{~s}, 3 \mathrm{H}, \mathrm{OCH}_{3}\right)$, 3.35 (bs, $\left.1 \mathrm{H}, \mathrm{H}_{11}\right), 3.13\left(\mathrm{dd}, J=17.8,5.5 \mathrm{~Hz}, 1 \mathrm{H}, \mathrm{H}_{6}\right), 2.91\left(\mathrm{~m}, 1 \mathrm{H}, \mathrm{H}_{6}\right), 2.68\left(\mathrm{bs}, 1 \mathrm{H}, \mathrm{H}_{7}\right), 2.38(\mathrm{~m}, 1 \mathrm{H}$, $\left.\mathrm{H}_{10}\right), 1.85\left(\mathrm{~m}, 3 \mathrm{H}, \mathrm{H}_{10}, 2 \times \mathrm{H}_{13}\right), 1.50\left(\mathrm{~s}, 3 \mathrm{H}, \mathrm{CH}_{3}\right) .{ }^{13} \mathrm{C}-\mathrm{NMR}\left(\mathrm{DMSO}-d_{6}\right): \delta 157.0\left(\mathrm{C}_{2}\right), 153.6\left(\mathrm{C}_{12}\right)$, $148.8\left(\mathrm{C}_{\mathrm{q}}\right), 133.2\left(\mathrm{C}_{\mathrm{q}}\right), 132.6\left(\mathrm{C}_{\mathrm{q}}\right), 124.5\left(\mathrm{C}_{3}\right), 124.2\left(\mathrm{C}_{8}\right), 120.8\left(\mathrm{C}_{4}\right), 116.4\left(\mathrm{C}_{\mathrm{q}}\right), 112.9\left(\mathrm{C}_{\mathrm{q}}\right), 103.1\left(\mathrm{C}_{1}\right), 56.5$ $\left(\mathrm{OCH}_{3}\right), 35.2\left(\mathrm{C}_{10}\right), 34.3\left(\mathrm{C}_{6}\right), 28.0\left(\mathrm{C}_{13}\right), 26.5\left(\mathrm{C}_{7}\right), 25.6\left(\mathrm{C}_{11}\right), 23.3\left(\mathrm{CH}_{3}\right)$. HESI-HRMS: $m / z$ : calcd. for $\mathrm{C}_{18} \mathrm{H}_{21} \mathrm{~N}_{2} \mathrm{O}: 281.1609[\mathrm{M}+\mathrm{H}]^{+}$found 281.1623.

\subsection{Biochemical Studies}

\subsubsection{In Vitro Anti-Cholinesterase Assay}

The inhibitory activities of $( \pm)-\mathbf{1} \cdot \mathrm{HCl}$ and all the standards against human recombinant AChE (hAChE, E.C. 3.1.1.7, purchased from Sigma-Aldrich, Prague, Czech Republic) and human plasmatic BChE (hBChE, E.C. 3.1.1.8, purchased from Sigma-Aldrich, Prague, Czech Republic) were determined 
using modified Ellman's method [34-36] and are expressed as $\mathrm{IC}_{50}$ (the concentration of the compound that is required to reduce $50 \%$ of cholinesterase activity). Other used compounds were phosphate buffer solution (PBS, $\mathrm{pH}=7.4$ ), 5,5'-dithio-bis(2-nitrobenzoic) acid (Ellman's reagent, DTNB), acetylthiocholine (ATCh), and butyrylthiocholine (BTCh) were also commercially available and were purchased from Sigma-Aldrich (Prague, Czech Republic). During the measurement, 96-well microplates from polystyrene (ThermoFisher Scientific, Waltham, MA, USA) were used. The solutions of corresponding enzyme in PBS were prepared up to final activity $0.002 \mathrm{U} / \mu \mathrm{L}$. The assay medium $(100 \mu \mathrm{L})$ consisted of cholinesterase $(10 \mu \mathrm{L})$, DTNB $(20 \mu \mathrm{L}$ of $0.01 \mathrm{M}$ solution) and PBS (40 $\mu \mathrm{L}$ of $0.1 \mathrm{M}$ solution). The solutions of the tested compounds ( $10 \mu \mathrm{L}$ of different concentrations) were pre-incubated for $5 \mathrm{~min}$ in the assay medium and then solution of substrate $(20 \mu \mathrm{L}$ of $0.01 \mathrm{M}$ ATCh or BTCh iodide solution) was added to initiate the reaction. The increase of absorbance was measured at $412 \mathrm{~nm}$ using Multimode microplate reader Synergy 2 (BioTek Inc., Winooski, VT, USA). For the calculation of the resulting measured activity (the percentage of inhibition I) following formula was used:

$$
I=\left(1-\frac{\Delta A_{i}}{\Delta A_{0}}\right) \times 100
$$

where $\Delta A_{i}$ indicates absorbance change provided by adequate enzyme exposed to corresponding inhibitor and $\triangle A_{0}$ indicates absorbance change when a solution of PBS was added instead of a solution of inhibitor. Software Microsoft Excel (Redmont, WA, USA) and GraphPad Prism version 5.02 for Windows (GraphPad Software, San Diego, CA, USA) were used for the statistical data evaluation.

\subsubsection{Kinetic Study of AChE Inhibition}

The kinetic study of $h \mathrm{AChE}$ was performed by using above mentioned Ellman's method [34,35]. The concentrations of $( \pm)-1 \cdot \mathrm{HCl}$ used for the measurements were as follows: 1.00, 10.0, and $100 \mu \mathrm{M}$. The values of $V_{\max }$ and $K_{\mathrm{m}}$ of the Michaelis-Menten kinetics as well as the values of $K_{\mathrm{i}}$ and $K_{\mathrm{i}^{\prime}}$ were calculated by non-linear regression from the substrate velocity curves. Linear regression was used for calculation of Lineweaver-Burk plots. All calculations were performed using GraphPad Prism software version 5.02 for Windows (San Diego, CA, USA).

\subsubsection{Determination of In Vitro Blood-Brain Barrier Permeation}

For the prediction of $( \pm)-\mathbf{1} \cdot \mathrm{HCl}$ and $( \pm)$-HupY $\cdot \mathrm{HCl}$ to passively penetrate the $\mathrm{BBB}$, the PAMPA protocol was used [50,51]. Briefly, the filter membrane of the donor plate was coated with PBL (Polar Brain Lipid, Avanti, St. Normal, IL, USA) in dodecane (4 $\mu \mathrm{L}$ of $20 \mathrm{mg} / \mathrm{mL}$ PBL in dodecane) and the acceptor well was filled with $300 \mu \mathrm{L}$ of PBS pH 7.4 buffer (VD). Tested compounds were dissolved first in DMSO and diluted with PBS pH 7.4 to reach the final concentration $100 \mu \mathrm{M}$ in the donor well. Concentration of DMSO did not exceed $0.5 \%(v / v)$ in the donor solution. Next, $300 \mu \mathrm{L}$ of the donor solution was added to the donor wells (VA) and the donor filter plate was carefully put on the acceptor plate so that coated membrane was "in touch" with both donor solution and acceptor buffer. Test compound diffused from the donor well through the lipid membrane (Area $=0.28 \mathrm{~cm}^{2}$ ) to the acceptor well. The concentration of the drug in both donor and the acceptor wells was assessed after 3, 4, 5, and $6 \mathrm{~h}$ of incubation in quadruplicate using the UV plate reader Synergy HT (Biotek, Winooski, VT, USA) at the maximum absorption wavelength of each compound. Concentration of the compounds was calculated from the standard curve and expressed as the permeability $(\mathrm{Pe})$ according the equation $[65,66]$ :

$$
\log P_{e}=\log \left\{C \times \ln \left(1-\frac{[\text { drug }]_{\text {aceptor }}}{[\text { drug }]_{\text {equilibrium }}}\right)\right\}
$$

where $C=\frac{\left(V_{D} \times V_{A}\right)}{\left(V_{D}+V_{A}\right) \text { Area } \times \text { time }}$. 


\subsubsection{Evaluation of Cytotoxicity by MTT Assay}

Cytotoxicity of tested compounds was evaluated by standard MTT assay [56] using the HepG2 cell line originally from human liver hepatocellular carcinoma, ACHN cell line of human renal adenocarcinoma, SH-SY5Y cell line of human neuroblastoma (ACTCC, USA). HepG2, ACHN, and SH-SY5Y cells were plated at density $17-30 \times 10^{3}$ per well in a 96-well plate in Dulbecco's Modified Eagle's Medium (DMEM, Biowest, Riverside, MO, USA) or DMEM-F12 (Biowest, Riverside, MO, USA) with 10\% FBS (Gibco, Langley, OK, USA) and were left unattached overnight. The incubation was performed under these conditions: $37{ }^{\circ} \mathrm{C}, 5 \% \mathrm{CO}_{2}$ and $80-95 \%$ air humidity. Stock solutions of tested compounds were prepared in dimethyl sulfoxide (DMSO, Sigma-Aldrich, Prague, Czech Republic) and then diluted in DMEM or DMEM-F12 medium. The final concentration of DMSO was less than 0.5\%.

The cell viability was detected using (3-4,5-dimethylthiazol-2-yl)-2,5-diphenyltetrazolium bromide (MTT; Sigma-Aldrich, Prague, Czech Republic) assay [56] after $24 \mathrm{~h}$ of incubation with compounds. Subsequently, the medium was aspirated and 10-100 $\mu$ L MTT solution in serum- and phenol red-free DMEM medium was added to each well. Cells were then incubated for $1-3 \mathrm{~h}$. The medium was then discarded and purple crystals of MTT formazan were dissolved in $100 \mu \mathrm{L}$ DMSO under shaking. The absorbance was measured with a microplate (Biotek Inc., Winooski, VT, USA) at a test wavelength of $570 \mathrm{~nm}$.

The $\mathrm{IC}_{50}$ values were calculated using four parametric nonlinear regression with statistic software GraphPad Prism (GraphPad Software, Inc., San Diego, CA, USA). Data were obtained from three independent experiments performed in duplicates or triplicates. $\mathrm{IC}_{50}$ values were expressed as mean \pm SEM.

\subsection{Molecular Modeling Studies}

Two structures of $h \mathrm{AChE}$ and $h \mathrm{BChE}$ were gained from the RCSB Protein Data Bank-PDB ID: 4EY7 (crystal structure of $h \mathrm{AChE}$ ) and 4BDS (crystal structure of $h \mathrm{BChE}$ ) $[63,64]$. All receptor structures were prepared by the DockPrep function of UCSF Chimera (version 1.4) and converted to pdbqt-files by AutodockTools (v. 1.5.6) $[67,68]$. Flexible residues selection was based on previous experience ( $h \mathrm{AChE}$ ) or spherical region around the binding cavity [69-75].

Three-dimensional structures of ligands were built by Open Babel (v. 2.3.1), minimized by Avogadro (v 1.1.0), and converted to pdbqt-file format by AutodockTools [76]. The docking calculations were done by Autodock Vina (v. 1.1.2) with the exhaustiveness of 8 [77]. Calculation was repeated 15 times for each ligand and receptor and the best-scored result was selected for manual inspection. The visualization of enzyme-ligand interactions was prepared using 1.3. (The PyMOL Molecular Graphics System, Version 1.5.0.4 Schrödinger, LLC, Mannheim, Germany). 2D diagrams were created with PoseView software.

\section{Conclusions}

Although THA was withdrawn from the market due to its side effects, it still represents a valuable scaffold for the design of novel potential anti-AD agents. Examples of such compounds are 7-MEOTA and HupY. 7-MEOTA is a derivative of THA that has interesting pharmacological profile while having suppressed hepatotoxicity. HupY is a combination of THA and (-)-huperzine A, both being potent inhibitors of $\mathrm{ChE}$, and as such showing high inhibitory activity against $\mathrm{AChE}$. We report here the design, synthesis, and pharmacological profile of novel huprine, namely 2-methoxyhuprine, sharing structural features of 7-MEOTA and HupY. The design strategy of $( \pm)$-1 yielded non-selective mixed type (on $h \mathrm{AChE}$ ) ChEI with balanced physicochemical properties. In silico studies predicted that the more active enantiomer was $7 S, 11 S-\mathbf{1}$ for $h \mathrm{AChE}$, while $h \mathrm{BChE}$ can be more potently inhibited by $7 R, 11 R-1$. The final confirmation of the work presented here requires firstly enantiomer separation followed by a biological assessment. Taken together, our study enriches the pipeline of lead compounds for further development of huprine derivatives potentially applicable for AD treatment. 
Acknowledgments: The work was supported by Ministry of Health of the Czech Republic, grant No. 15-30954A by COST Action CA15135, by the project No. LO1611 with a financial support from the MEYS under the NPU I program, by the grant of Ministry of Defence "Long Term Development Plan". Computational resources were supplied by the Ministry of Education, Youth and Sports of the Czech Republic under the Projects CESNET (Project No. LM2015042) and CERIT-Scientific Cloud (Project No. LM2015085) provided within the program Projects of Large Research, Development and Innovations Infrastructures.

Author Contributions: Eva Mezeiova and Jan Korabecny carried out the synthesis, interpretation of corresponding spectra and wrote the manuscript. Lucia Pokrievkova, Katarina Spilovska and Jaroslav Roh assisted with the synthesis. Jan Korabecny and Tomas Kucera performed molecular modeling study. Vendula Sepsova and Martina Hrabinova performed the cholinesterase inhibition. Petr Jost, Lubica Muckova and Jan Misik performed the MTT assay. Rafael Dolezal performed HRMS analysis. Ngoc Lam Pham evaluated physicochemical properties. Katarina Spilovska performed spectra analysis. Daniel Jun performed the kinetic study. Ondrej Soukup performed the PAMPA assay. Kamil Kuca and Daniel Kaping supervised the study. All authors contributed to and have approved the final manuscript.

Conflicts of Interest: The authors declare no conflict of interest.

\section{References}

1. Barage, S.H.; Sonawane, K.D. Amyloid cascade hypothesis: Pathogenesis and therapeutic strategies in Alzheimer's disease. Neuropeptides 2015, 52, 1-18. [CrossRef] [PubMed]

2. Maresova, P.; Klimova, B.; Novotny, M.; Kuca, K. Alzheimer's and Parkinson's Diseases: Expected Economic Impact on Europe-A Call for a Uniform European Strategy. J. Alzheimers Dis. JAD 2016, 54, 1123-1133. [CrossRef] [PubMed]

3. Marešová, P.; Mohelská, H.; Dolejš, J.; Kuča, K. Socio-economic Aspects of Alzheimer's Disease. Curr. Alzheimer Res. 2015, 12, 903-911. [CrossRef] [PubMed]

4. Zemek, F.; Drtinova, L.; Nepovimova, E.; Sepsova, V.; Korabecny, J.; Klimes, J.; Kuca, K. Outcomes of Alzheimer's disease therapy with acetylcholinesterase inhibitors and memantine. Expert Opin. Drug Saf. 2014, 13, 759-774. [CrossRef] [PubMed]

5. Spilovska, K.; Zemek, F.; Korabecny, J.; Nepovimova, E.; Soukup, O.; Windisch, M.; Kuca, K. Adamantane-A Lead Structure for Drugs in Clinical Practice. Curr. Med. Chem. 2016, 23, 3245-3266. [CrossRef] [PubMed]

6. Horak, M.; Holubova, K.; Nepovimova, E.; Krusek, J.; Kaniakova, M.; Korabecny, J.; Vyklicky, L.; Kuca, K.; Stuchlik, A.; Ricny, J.; et al. The pharmacology of tacrine at N-methyl-D-aspartate receptors. Prog. Neuropsychopharmacol. Biol. Psychiatry 2017, 75, 54-62. [CrossRef] [PubMed]

7. Zhu, Y.; Xiao, K.; Ma, L.; Xiong, B.; Fu, Y.; Yu, H.; Wang, W.; Wang, X.; Hu, D.; Peng, H.; et al. Design, synthesis and biological evaluation of novel dual inhibitors of acetylcholinesterase and beta-secretase. Bioorg. Med. Chem. 2009, 17, 1600-1613. [CrossRef] [PubMed]

8. Rampa, A.; Mancini, F.; De Simone, A.; Falchi, F.; Belluti, F.; Di Martino, R.M.C.; Gobbi, S.; Andrisano, V.; Tarozzi, A.; Bartolini, M.; et al. From AChE to BACE1 inhibitors: The role of the amine on the indanone scaffold. Bioorg. Med. Chem. Lett. 2015, 25, 2804-2808. [CrossRef] [PubMed]

9. Costanzo, P.; Cariati, L.; Desiderio, D.; Sgammato, R.; Lamberti, A.; Arcone, R.; Salerno, R.; Nardi, M.; Masullo, M.; Oliverio, M. Design, Synthesis, and Evaluation of Donepezil-Like Compounds as AChE and BACE-1 Inhibitors. ACS Med. Chem. Lett. 2016, 7, 470-475. [CrossRef] [PubMed]

10. Viayna, E.; Sabate, R.; Muñoz-Torrero, D. Dual inhibitors of $\beta$-amyloid aggregation and acetylcholinesterase as multi-target anti-Alzheimer drug candidates. Curr. Top. Med. Chem. 2013, 13, 1820-1842. [CrossRef] [PubMed]

11. Ortega, A.; Rincón, Á.; Jiménez-Aliaga, K.L.; Bermejo-Bescós, P.; Martín-Aragón, S.; Molina, M.T.; Csák̈̈, A.G. Synthesis and evaluation of arylquinones as BACE1 inhibitors, $\beta$-amyloid peptide aggregation inhibitors, and destabilizers of preformed $\beta$-amyloid fibrils. Bioorg. Med. Chem. Lett. 2011, 21, 2183-2187. [CrossRef] [PubMed]

12. Panek, D.; Więckowska, A.; Wichur, T.; Bajda, M.; Godyń, J.; Jończyk, J.; Mika, K.; Janockova, J.; Soukup, O.; Knez, D.; et al. Design, synthesis and biological evaluation of new phthalimide and saccharin derivatives with alicyclic amines targeting cholinesterases, beta-secretase and amyloid beta aggregation. Eur. J. Med. Chem. 2016, 125, 676-695. [CrossRef] [PubMed]

13. Mohandas, E.; Rajmohan, V.; Raghunath, B. Neurobiology of Alzheimer's disease. Indian J. Psychiatry 2009, 51, 55-61. [CrossRef] [PubMed] 
14. Selkoe, D.J.; Hardy, J. The amyloid hypothesis of Alzheimer's disease at 25 years. EMBO Mol. Med. 2016, 8 , 595-608. [CrossRef] [PubMed]

15. Babkova, K.; Korabecny, J.; Soukup, O.; Nepovimova, E.; Jun, D.; Kuca, K. Prolyl oligopeptidase and its role in the organism: Attention to the most promising and clinically relevant inhibitors. Future Med. Chem. 2017, 9, 1015-1038. [CrossRef] [PubMed]

16. Kuca, K.; Soukup, O.; Maresova, P.; Korabecny, J.; Nepovimova, E.; Klimova, B.; Honegr, J.; Ramalho, T.C.; França, T.C.C. Current Approaches Against Alzheimer's Disease in Clinical Trials. J. Braz. Chem. Soc. 2016, 27, 641-649. [CrossRef]

17. Soukup, O.; Jun, D.; Zdarova-Karasova, J.; Patocka, J.; Musilek, K.; Korabecny, J.; Krusek, J.; Kaniakova, M.; Sepsova, V.; Mandikova, J.; et al. A resurrection of 7-MEOTA: A comparison with tacrine. Curr. Alzheimer Res. 2013, 10, 893-906. [CrossRef] [PubMed]

18. Korabecny, J.; Musilek, K.; Zemek, F.; Horova, A.; Holas, O.; Nepovimova, E.; Opletalova, V.; Hroudova, J.; Fisar, Z.; Jung, Y.-S.; et al. Synthesis and in vitro evaluation of 7-methoxy-N-(pent-4-enyl)-1,2,3,4tetrahydroacridin-9-amine-new tacrine derivate with cholinergic properties. Bioorg. Med. Chem. Lett. 2011, 21, 6563-6566. [CrossRef] [PubMed]

19. Korabecny, J.; Musilek, K.; Holas, O.; Binder, J.; Zemek, F.; Marek, J.; Pohanka, M.; Opletalova, V.; Dohnal, V.; Kuca, K. Synthesis and in vitro evaluation of N-alkyl-7-methoxytacrine hydrochlorides as potential cholinesterase inhibitors in Alzheimer disease. Bioorg. Med. Chem. Lett. 2010, 20, 6093-6095. [CrossRef] [PubMed]

20. Patocka, J.; Jun, D.; Kuca, K. Possible role of hydroxylated metabolites of tacrine in drug toxicity and therapy of Alzheimer's disease. Curr. Drug Metab. 2008, 9, 332-335. [CrossRef] [PubMed]

21. Muñoz-Torrero, D.; Camps, P. Huprines for Alzheimer's disease drug development. Expert Opin. Drug Discov. 2008, 3, 65-81. [CrossRef] [PubMed]

22. Harel, M.; Schalk, I.; Ehret-Sabatier, L.; Bouet, F.; Goeldner, M.; Hirth, C.; Axelsen, P.H.; Silman, I.; Sussman, J.L. Quaternary ligand binding to aromatic residues in the active-site gorge of acetylcholinesterase. Proc. Natl. Acad. Sci. USA 1993, 90, 9031-9035. [CrossRef] [PubMed]

23. Raves, M.L.; Harel, M.; Pang, Y.P.; Silman, I.; Kozikowski, A.P.; Sussman, J.L. Structure of acetylcholinesterase complexed with the nootropic alkaloid, (-)-huperzine A. Nat. Struct. Biol. 1997, 4, 57-63. [CrossRef] [PubMed]

24. Dvir, H.; Wong, D.M.; Harel, M.; Barril, X.; Orozco, M.; Luque, F.J.; Muñoz-Torrero, D.; Camps, P.; Rosenberry, T.L.; Silman, I.; et al. 3D structure of Torpedo californica acetylcholinesterase complexed with huprine $X$ at 2.1 A resolution: Kinetic and molecular dynamic correlates. Biochemistry (Mosc.) 2002, 41, 2970-2981. [CrossRef]

25. Gabrielson, K.L.; Hogue, B.A.; Bohr, V.A.; Cardounel, A.J.; Nakajima, W.; Kofler, J.; Zweier, J.L.; Rodriguez, E.R.; Martin, L.J.; de Souza-Pinto, N.C.; et al. Mitochondrial toxin 3-nitropropionic acid induces cardiac and neurotoxicity differentially in mice. Am. J. Pathol. 2001, 159, 1507-1520. [CrossRef]

26. Canudas, A.M.; Pubill, D.; Sureda, F.X.; Verdaguer, E.; Camps, P.; Muñoz-Torrero, D.; Jiménez, A.; Camins, A.; Pallàs, M. Neuroprotective effects of $( \pm)$-huprine $Y$ on in vitro and in vivo models of excitoxicity damage. Exp. Neurol. 2003, 180, 123-130. [CrossRef]

27. Yu, J.; Jin, Y.; Lu, M. 3-Methyl-4-oxa-5-azahomoadamantane as an Organocatalyst for the Aerobic Oxidation of Primary Amines to Oximes in Water. Adv. Synth. Catal. 2015, 357, 1175-1180. [CrossRef]

28. Denmark, S.E.; Henke, B.R. Investigations on transition-state geometry in the aldol condensation. J. Am. Chem. Soc. 1989, 111, 8032-8034. [CrossRef]

29. Camps, P.; Contreras, J.; Font-Bardia, M.; Morral, J.; Muñoz-Torrero, D.; Solans, X. Enantioselective synthesis of tacrine-huperzine A hybrids. Preparative chiral MPLC separation of their racemic mixtures and absolute configuration assignments by X-ray diffraction analysis. Tetrahedron Asymmetry 1998, 9, 835-849. [CrossRef]

30. Lynch, T.J.; Mattes, C.E.; Singh, A.; Bradley, R.M.; Brady, R.O.; Dretchen, K.L. Cocaine detoxification by human plasma butyrylcholinesterase. Toxicol. Appl. Pharmacol. 1997, 145, 363-371. [CrossRef] [PubMed]

31. Long, J.Z.; Cravatt, B.F. The metabolic serine hydrolases and their functions in mammalian physiology and disease. Chem. Rev. 2011, 111, 6022-6063. [CrossRef] [PubMed]

32. Komloova, M.; Musilek, K.; Dolezal, M.; Gunn-Moore, F.; Kuca, K. Structure-activity relationship of quaternary acetylcholinesterase inhibitors-outlook for early myasthenia gravis treatment. Curr. Med. Chem. 2010, 17, 1810-1824. [CrossRef] [PubMed] 
33. Čolović, M.B.; Krstić, D.Z.; Lazarević-Pašti, T.D.; Bondžić, A.M.; Vasić, V.M. Acetylcholinesterase Inhibitors: Pharmacology and Toxicology. Curr. Neuropharmacol. 2013, 11, 315-335. [CrossRef] [PubMed]

34. Ellman, G.L.; Courtney, K.D.; Andres, V.; Feather-Stone, R.M. A new and rapid colorimetric determination of acetylcholinesterase activity. Biochem. Pharmacol. 1961, 7, 88-95. [CrossRef]

35. Pohanka, M.; Karasova, J.Z.; Kuca, K.; Pikula, J.; Holas, O.; Korabecny, J.; Cabal, J. Colorimetric dipstick for assay of organophosphate pesticides and nerve agents represented by paraoxon, sarin and VX. Talanta 2010, 81, 621-624. [CrossRef] [PubMed]

36. Sepsova, V.; Karasova, J.Z.; Korabecny, J.; Dolezal, R.; Zemek, F.; Bennion, B.J.; Kuca, K. Oximes: Inhibitors of human recombinant acetylcholinesterase. A structure-activity relationship (SAR) study. Int. J. Mol. Sci. 2013, 14, 16882-16900. [CrossRef] [PubMed]

37. Pohanka, M.; Jun, D.; Kuca, K. Improvement of acetylcholinesterase-based assay for organophosphates in way of identification by reactivators. Talanta 2008, 77, 451-454. [CrossRef] [PubMed]

38. Recanatini, M.; Cavalli, A.; Belluti, F.; Piazzi, L.; Rampa, A.; Bisi, A.; Gobbi, S.; Valenti, P.; Andrisano, V.; Bartolini, M.; et al. SAR of 9-amino-1,2,3,4-tetrahydroacridine-based acetylcholinesterase inhibitors: Synthesis, enzyme inhibitory activity, QSAR, and structure-based CoMFA of tacrine analogues. J. Med. Chem. 2000, 43, 2007-2018. [CrossRef] [PubMed]

39. Camps, P.; El Achab, R.; Morral, J.; Muñoz-Torrero, D.; Badia, A.; Baños, J.E.; Vivas, N.M.; Barril, X.; Orozco, M.; Luque, F.J. New Tacrine-Huperzine A Hybrids (Huprines): Highly Potent Tight-Binding Acetylcholinesterase Inhibitors of Interest for the Treatment of Alzheimer's Disease. J. Med. Chem. 2000, 43, 4657-4666. [CrossRef] [PubMed]

40. Giacobini, E. Selective inhibitors of butyrylcholinesterase: A valid alternative for therapy of Alzheimer's disease? Drugs Aging 2001, 18, 891-898. [CrossRef] [PubMed]

41. Nordberg, A.; Ballard, C.; Bullock, R.; Darreh-Shori, T.; Somogyi, M. A review of butyrylcholinesterase as a therapeutic target in the treatment of Alzheimer's disease. Prim. Care Companion CNS Disord. 2013, 15. [CrossRef]

42. Lahiri, D.K.; Farlow, M.R.; Hintz, N.; Utsuki, T.; Greig, N.H. Cholinesterase inhibitors, beta-amyloid precursor protein and amyloid beta-peptides in Alzheimer's disease. Acta Neurol. Scand. Suppl. 2000, 176, 60-67. [CrossRef] [PubMed]

43. Inestrosa, N.C.; Alvarez, A.; Pérez, C.A.; Moreno, R.D.; Vicente, M.; Linker, C.; Casanueva, O.I.; Soto, C.; Garrido, J. Acetylcholinesterase accelerates assembly of amyloid-beta-peptides into Alzheimer's fibrils: Possible role of the peripheral site of the enzyme. Neuron 1996, 16, 881-891. [CrossRef]

44. Pang, Y.P.; Quiram, P.; Jelacic, T.; Hong, F.; Brimijoin, S. Highly potent, selective, and low cost bis-tetrahydroaminacrine inhibitors of acetylcholinesterase. Steps toward novel drugs for treating Alzheimer's disease. J. Biol. Chem. 1996, 271, 23646-23649. [CrossRef] [PubMed]

45. Nepovimova, E.; Korabecny, J.; Dolezal, R.; Babkova, K.; Ondrejicek, A.; Jun, D.; Sepsova, V.; Horova, A.; Hrabinova, M.; Soukup, O.; et al. Tacrine-Trolox Hybrids: A Novel Class of Centrally Active, Nonhepatotoxic Multi-Target-Directed Ligands Exerting Anticholinesterase and Antioxidant Activities with Low In Vivo Toxicity. J. Med. Chem. 2015, 58, 8985-9003. [CrossRef] [PubMed]

46. Nepovimova, E.; Uliassi, E.; Korabecny, J.; Peña-Altamira, L.E.; Samez, S.; Pesaresi, A.; Garcia, G.E.; Bartolini, M.; Andrisano, V.; Bergamini, C.; et al. Multitarget drug design strategy: Quinone-tacrine hybrids designed to block amyloid- $\beta$ aggregation and to exert anticholinesterase and antioxidant effects. J. Med. Chem. 2014, 57, 8576-8589. [CrossRef] [PubMed]

47. Spilovska, K.; Korabecny, J.; Horova, A.; Musilek, K.; Nepovimova, E.; Drtinova, L.; Gazova, Z.; Siposova, K.; Dolezal, R.; Jun, D.; et al. Design, synthesis and in vitro testing of 7-methoxytacrine-amantadine analogues: A novel cholinesterase inhibitors for the treatment of Alzheimer's disease. Med. Chem. Res. 2015, 1-11. [CrossRef]

48. Spilovska, K.; Korabecny, J.; Kral, J.; Horova, A.; Musilek, K.; Soukup, O.; Drtinova, L.; Gazova, Z.; Siposova, K.; Kuca, K. 7-Methoxytacrine-adamantylamine heterodimers as cholinesterase inhibitors in Alzheimer's disease treatment—Synthesis, biological evaluation and molecular modeling studies. Molecules 2013, 18, 2397-2418. [CrossRef] [PubMed]

49. Alcalá, M. del M.; Vivas, N.M.; Hospital, S.; Camps, P.; Muñoz-Torrero, D.; Badia, A. Characterisation of the anticholinesterase activity of two new tacrine-huperzine A hybrids. Neuropharmacology 2003, 44, 749-755. [CrossRef] 
50. Di, L.; Kerns, E.H.; Fan, K.; McConnell, O.J.; Carter, G.T. High throughput artificial membrane permeability assay for blood-brain barrier. Eur. J. Med. Chem. 2003, 38, 223-232. [CrossRef]

51. Lemes, L.F.N.; de Andrade Ramos, G.; de Oliveira, A.S.; da Silva, F.M.R.; de Castro Couto, G.; da Silva Boni, M.; Guimarães, M.J.R.; Souza, I.N.O.; Bartolini, M.; Andrisano, V.; et al. Cardanol-derived AChE inhibitors: Towards the development of dual binding derivatives for Alzheimer's disease. Eur. J. Med. Chem. 2016, 108, 687-700. [CrossRef] [PubMed]

52. Spilovska, K.; Korabecny, J.; Sepsova, V.; Jun, D.; Hrabinova, M.; Jost, P.; Muckova, L.; Soukup, O.; Janockova, J.; Kucera, T.; et al. Novel Tacrine-Scutellarin Hybrids as Multipotent Anti-Alzheimer's Agents: Design, Synthesis and Biological Evaluation. Molecules 2017, 22, 1006. [CrossRef] [PubMed]

53. Gazova, Z.; Soukup, O.; Sepsova, V.; Siposova, K.; Drtinova, L.; Jost, P.; Spilovska, K.; Korabecny, J.; Nepovimova, E.; Fedunova, D.; et al. Multi-target-directed therapeutic potential of 7-methoxytacrine-adamantylamine heterodimers in the Alzheimer's disease treatment. Biochim. Biophys. Acta 2017, 1863, 607-619. [CrossRef] [PubMed]

54. Wager, T.T.; Hou, X.; Verhoest, P.R.; Villalobos, A. Moving beyond rules: The development of a central nervous system multiparameter optimization (CNS MPO) approach to enable alignment of druglike properties. ACS Chem. Neurosci. 2010, 1, 435-449. [CrossRef] [PubMed]

55. Wager, T.T.; Hou, X.; Verhoest, P.R.; Villalobos, A. Central Nervous System Multiparameter Optimization Desirability: Application in Drug Discovery. ACS Chem. Neurosci. 2016, 7, 767-775. [CrossRef] [PubMed]

56. Mosmann, T. Rapid colorimetric assay for cellular growth and survival: Application to proliferation and cytotoxicity assays. J. Immunol. Methods 1983, 65, 55-63. [CrossRef]

57. Spaldin, V.; Madden, S.; Pool, W.F.; Woolf, T.F.; Park, B.K. The effect of enzyme inhibition on the metabolism and activation of tacrine by human liver microsomes. Br. J. Clin. Pharmacol. 1994, 38, 15-22. [CrossRef] [PubMed]

58. Monteith, D.K.; Theiss, J.C. Comparison of tacrine-induced cytotoxicity in primary cultures of rat, mouse, monkey, dog, rabbit, and human hepatocytes. Drug Chem. Toxicol. 1996, 19, 59-70. [CrossRef] [PubMed]

59. Galisteo, M.; Rissel, M.; Sergent, O.; Chevanne, M.; Cillard, J.; Guillouzo, A.; Lagadic-Gossmann, D. Hepatotoxicity of tacrine: Occurrence of membrane fluidity alterations without involvement of lipid peroxidation. J. Pharmacol. Exp. Ther. 2000, 294, 160-167. [PubMed]

60. Terrell, P.S.; Bredenkamp, V.L.; Lammers, J.E. Null Late-onset alanine aminotransferase increase with tacrine. Ann. Pharmacother. 1996, 30, 301. [CrossRef] [PubMed]

61. Roberts, C.J.; Ford, J.M.; Truman, C.A.; Scott, M.; Mäkelä, P.M.; Wilcock, G.K. Assessment of the value of therapeutic monitoring of tacrine in Alzheimer's disease. Eur. J. Clin. Pharmacol. 1998, 54, 721-724. [CrossRef] [PubMed]

62. Jeřábek, J.; Uliassi, E.; Guidotti, L.; Korábečný, J.; Soukup, O.; Sepsova, V.; Hrabinova, M.; Kuča, K.; Bartolini, M.; Peña-Altamira, L.E.; et al. Tacrine-resveratrol fused hybrids as multi-target-directed ligands against Alzheimer's disease. Eur. J. Med. Chem. 2017, 127, 250-262. [CrossRef] [PubMed]

63. Cheung, J.; Rudolph, M.J.; Burshteyn, F.; Cassidy, M.S.; Gary, E.N.; Love, J.; Franklin, M.C.; Height, J.J. Structures of human acetylcholinesterase in complex with pharmacologically important ligands. J. Med. Chem. 2012, 55, 10282-10286. [CrossRef] [PubMed]

64. Nachon, F.; Carletti, E.; Ronco, C.; Trovaslet, M.; Nicolet, Y.; Jean, L.; Renard, P.-Y. Crystal structures of human cholinesterases in complex with huprine W and tacrine: Elements of specificity for anti-Alzheimer's drugs targeting acetyl- and butyryl-cholinesterase. Biochem. J. 2013, 453, 393-399. [CrossRef] [PubMed]

65. Sugano, K.; Hamada, H.; Machida, M.; Ushio, H. High throughput prediction of oral absorption: Improvement of the composition of the lipid solution used in parallel artificial membrane permeation assay. J. Biomol. Screen. 2001, 6, 189-196. [CrossRef] [PubMed]

66. Wohnsland, F.; Faller, B. High-throughput permeability $\mathrm{pH}$ profile and high-throughput alkane/water log $\mathrm{P}$ with artificial membranes. J. Med. Chem. 2001, 44, 923-930. [CrossRef] [PubMed]

67. Pettersen, E.F.; Goddard, T.D.; Huang, C.C.; Couch, G.S.; Greenblatt, D.M.; Meng, E.C.; Ferrin, T.E. UCSF Chimera-A visualization system for exploratory research and analysis. J. Comput. Chem. 2004, 25, 1605-1612. [CrossRef] [PubMed]

68. Morris, G.M.; Huey, R.; Lindstrom, W.; Sanner, M.F.; Belew, R.K.; Goodsell, D.S.; Olson, A.J. AutoDock4 and AutoDockTools4: Automated docking with selective receptor flexibility. J. Comput. Chem. 2009, 30, 2785-2791. [CrossRef] [PubMed] 
69. Lee Kwang, S.; Park Kyun, M.; Yi, J.; Won Cho, D.; Sup Ra, C.; Musilek, K.; Horova, A.; Korabecny, J.; Dolezal, R.; Jun, D.; Kuca, K. Preparation of 7-methoxy tacrine dimer analogs and their in vitro/in silico evaluation as potential choliensterase inhibitors. Bull. Korean Chem. Soc. 2015. [CrossRef]

70. Dolezal, R.; Korabecny, J.; Malinak, D.; Honegr, J.; Musilek, K.; Kuca, K. Ligand-based 3D QSAR analysis of reactivation potency of mono- and bis-pyridinium aldoximes toward VX-inhibited rat acetylcholinesterase. J. Mol. Graph. Model. 2015, 56, 113-129. [CrossRef] [PubMed]

71. Korabecny, J.; Dolezal, R.; Cabelova, P.; Horova, A.; Hruba, E.; Ricny, J.; Sedlacek, L.; Nepovimova, E.; Spilovska, K.; Andrs, M.; et al. 7-MEOTA-donepezil like compounds as cholinesterase inhibitors: Synthesis, pharmacological evaluation, molecular modeling and QSAR studies. Eur. J. Med. Chem. 2014, 82, 426-438. [CrossRef] [PubMed]

72. Korabecny, J.; Musilek, K.; Holas, O.; Nepovimova, E.; Jun, D.; Zemek, F.; Opletalova, V.; Patocka, J.; Dohnal, V.; Nachon, F.; et al. Synthesis and in vitro evaluation of N-(Bromobut-3-en-2-yl)-7-methoxy-1,2,3,4tetrahydroacridin-9-amine as a cholinesterase inhibitor with regard to Alzheimer's disease treatment. Molecules 2010, 15, 8804-8812. [CrossRef] [PubMed]

73. Korabecny, J.; Andrs, M.; Nepovimova, E.; Dolezal, R.; Babkova, K.; Horova, A.; Malinak, D.; Mezeiova, E.; Gorecki, L.; Sepsova, V.; et al. 7-Methoxytacrine-P-Anisidine Hybrids as Novel Dual Binding Site Acetylcholinesterase Inhibitors for Alzheimer's Disease Treatment. Molecules 2015, 20, 22084-22101. [CrossRef] [PubMed]

74. Korabecny, J.; Holas, O.; Musilek, K.; Pohanka, M.; Opletalova, V.; Dohnal, V.; Kuca, K. Synthesis and In Vitro Evaluation of New Tacrine Derivates-Bis-Alkylene Linked 7-MEOTA. Lett. Org. Chem. 2010, 7, 327-331. [CrossRef]

75. Kristofikova, Z.; Ricny, J.; Soukup, O.; Korabecny, J.; Nepovimova, E.; Kuca, K.; Ripova, D. Inhibitors of Acetylcholinesterase Derived from 7-Methoxytacrine and Their Effects on the Choline Transporter CHT1. Dement. Geriatr. Cogn. Disord. 2017, 43, 45-58. [CrossRef] [PubMed]

76. O'Boyle, N.M.; Banck, M.; James, C.A.; Morley, C.; Vandermeersch, T.; Hutchison, G.R. Open Babel: An open chemical toolbox. J. Cheminform. 2011, 3, 33. [CrossRef] [PubMed]

77. Trott, O.; Olson, A.J. AutoDock Vina: Improving the speed and accuracy of docking with a new scoring function, efficient optimization, and multithreading. J. Comput. Chem. 2010, 31, 455-461. [CrossRef] [PubMed]

Sample Availability: Samples of the compounds are available from the authors.

(C) 2017 by the authors. Licensee MDPI, Basel, Switzerland. This article is an open access article distributed under the terms and conditions of the Creative Commons Attribution (CC BY) license (http:/ / creativecommons.org/licenses/by/4.0/). 